[This document contains the author's accepted manuscript. For the publisher's version, see the link in the header of this document.]

\title{
A Model of Melodic Expectation for Some Neo-Romantic Music of Penderecki
}

\author{
By Scott Murphy \\ Department of Music \\ University of Kansas
}

\section{Paper citation:}

Murphy, Scott. "A Model of Melodic Expectation in Some Neo-Romantic Music of Penderecki," Perspectives of New Music 25/1 (Winter 2007): 6-42. 
Murphy, Scott. "A Model of Melodic Expectation in Some Neo-Romantic Music of Penderecki," Perspectives of New Music 25/1 (Winter 2007 ): 6-42.

A Model of Melodic Expectation for Some Neo-Romantic Music of Penderecki

Example 1 provides a piano-score reduction of the first ten measures to Penderecki's First Violin Concerto (1977). This music functions as the orchestral exposition's slow introduction: the music that follows this excerpt introduces a quicker tempo, running sixteenth notes, and a new pedal point. Scholars generally agree that this concerto, along with his opera Paradise Lost (1978), are the two earliest major works from the composer's "neo-Romantic" period, although some perceive a foretaste of this new compositional direction in the short orchestral work The Awakening of Jacob (1974). ${ }^{1}$ Several features of this period - sometimes coexisting or interacting with Penderecki's “older" avant-garde techniques - conspicuously harken back to the common-practice style in general and the nineteenth century in particular: tertian harmonies, Wagnerian triadic progressions, Brucknerian creatio ex nihilo, traditional orchestration and instrumental doubling, continual developing variation, and protracted but not completely unfamiliar formal designs. Some of these can be heard in the ten measures of Example 1: the relentless F pedal point supports an interspersed Db-major harmony in mm. 1-5 and a shadowy tonicization of $\mathrm{F}$ minor, and wisps of meandering melodic material slowly emerge from this tonal adumbration in mm. 6-10.

One particular facet of the twilight of Romanticism that echoes in Penderecki's music is the adoption of tonal materials such as tertian harmonies but a neglect of common-practice syntax. Predominant-dominant-tonic progressions, expected resolutions of dissonances or active scale degrees (such as the leading tone), standard cadential formulas and the like are infrequent or completely absent—although more recent works, such as his Credo (1997) and De profundis (1998), give these features a larger role to play. The excerpt from the Violin Concerto offers a modest example of this neglect: each one of the four related melodic fragments in mm. 6-10 ends unresolved within the implicit F-minor tonality. The endings on B in particular, although Penderecki clearly 
treats them as points of arrival, hang suspended in the weak tonal field; a tonal hearing that is guided by the $\mathrm{F}$ pedal point would expect a $\mathrm{B}$ to resolve perhaps back up to $\mathrm{C}$ or to continue a descent to A or $\mathrm{Ab}$. Such tonal suspension is not without ample precedent in the music of the common-practice period; one can find corresponding moments in, for example, the music of Mozart. But Penderecki's concerto and other stylistically similar works differ from common practice in that they unremittingly frustrate such tonal expectations during their entire span.

And this continual frustration, both of tonal expectations and perhaps also of the listener who brings them alone, is arguably part of the music's aesthetic: the neoRomantic facade ostensibly promises tonal successions that are never delivered. Yet tonal expectations are not the only pitch-class expectations one may bring to this music. This study proposes the hypothesis that the highly constrained melodic style of Penderecki's neo-Romantic music avails another set of pitch-class expectations that, while not derived directly from tonal practice, are analogous to a rudimentary set of tonal expectations, and thus may be understood as a substitution for common-practice pitch-class expectations. Part I defines this melodic style from a pitch-class perspective, focusing on the two characteristics of pitch-class diversity and interval-class concentration. Part II then outlines the new expectancy model, and establishes an analogy between this model and certain models of tonal expectations. Part III applies the model to analyses of passages of Penderecki's music in this neo-Romantic style, and Part IV introduces graphical and tabular means of surveying Penderecki's melodic style and the complexity and richness of the expectancy model that this style engenders.

\section{Penderecki’s Melodic StYle(s)}

A feature of Penderecki's neo-Romantic period is often referred to, in some form or other, as "the reintroduction of melody." ${ }^{2}$ However, in the context of Penderecki's 
earlier music, this "reintroduction" may be better understood as a "whittling down," shearing off several of the composer's earlier avant-garde techniques, and resulting in a more focused and simplified presentation of a single-line pitch succession of which the low string lines of Example 1 are paradigmatic. First, Penderecki’s microtonal practices that dominated his earlier music take a back seat to the exclusive use of the twelve chromatic pitch classes (henceforth, pcs) during this period. ${ }^{3}$ Second, whereas most individual melodic lines are easily obscured by many other interwoven, concomitant melodic lines in the dense, polyphonic textures that frequent Penderecki's earlier music, his neo-Romantic music serves up a good helping of monophony. Third, and perhaps most simply, many of Penderecki's single-pitch lines in his earlier music are very fast, blurring any sense of a discrete pitch succession, while his neo-Romantic music includes many more moderately paced melodies.

Yet Penderecki's neo-Romantic melodies are hardly reversions to common practice: the "whittling down" metaphor is suggested because, at the core, two significant and generalizable features of Penderecki's melodies from his earlier music initially survive the shift into the neo-Romantic period. The first will be called pitch-class ( $p c)$ diversity, and the second interval-class (ic) concentration. ${ }^{4}$ Generally defined, a melody is pc-diverse to the degree that pc repetitions are fewer and farther apart than would occur by chance. A melody is ic-concentrated to the degree that the non-zero ordered pc intervals between its adjacent pitches are distributed more unevenly over the six interval classes than what would occur by chance. But before fleshing out these concepts with more precise definitions and examples, the issue of what does and does not constitute a melody in Penderecki's music requires some attention. For the purposes of this study, a melody is defined as a totally ordered succession of single chromatic pitches, relying on silence and other conventional means of segmentation to demarcate its beginning and ending. Furthermore, Penderecki occasionally builds his melodies by starting with a single note or handful of successive pitches, restating this kernel several times, and 
Murphy, Scott. "A Model of Melodic Expectation in Some Neo-Romantic Music of Penderecki," Perspectives of New Music 25/1 (Winter 2007 ): 6-42.

affixing one or more notes to the end of some or all of the restatements of the melody that carry over into the next statement. Often, these restatements are separated by silence, but even those that are not clearly project their process of accretion, usually by preserving registral position. Example 2, which provides the bass line for the section in the Violin Concerto that immediately follows the music of Example 1, displays one application of this procedure: the four-note repeated sequence $\mathrm{D}-\mathrm{D} \#-\mathrm{E}-\mathrm{F}$ first accrues to $\mathrm{D}-\mathrm{D} \#-\mathrm{E}-\mathrm{F}-\mathrm{B}-$ $\mathrm{B} b$ - $\mathrm{A}$ in mm. 15-16 and then immediately accrues to the full melody of $\mathrm{D}-\mathrm{D} \#-\mathrm{E}-\mathrm{F}-\mathrm{B}-\mathrm{B} b$ A-Ab-G-F\#-.... (The brackets below Example 2, which will be explained shortly, do not concern this accretion.) Therefore, in taking this practice into account, a melody under scrutiny should be purged of any interior repetitions, which are either immediate repetitions of a pc, or immediate repetitions of the same ordered sequence of pcs. ${ }^{5}$

Given this more narrow definition of a melody, pc diversity is relatively easy to come by in relatively short, randomly generated melodies. For example, any four-note pc succession without interior repetitions is $73 \%$ likely to be non-duplicative, that is, where all the pcs are different. This percentage lowers to just under chance (49\%) for five-note melodies. But from there, the odds drop off considerably: $27 \%$ for six notes, $13 \%$ for seven, and only 5\% for eight. In comparison, when examining Penderecki's melodic practice as a whole, the maximal lengths of non-duplicative successions of pcs without interior repetitions are on average nine notes, demonstrating a deliberate and efficient "composing-out" of the composer's familiar harmonic clusters. Penderecki scholar Ray Robinson comes close to this same figure in his assessment of the composer's overall melodic practice: "From Strophes (1959) to Violin Concerto No. 2 (1995), the linear material developed is based on a freely atonal scale model. There are times...where Penderecki is writing 'serial music'; there are others when he uses eight or nine units of the scale as the basis of constructing a freely atonal melodic line." 6 The melody played by the second 'cellos in mm. 6-7 of the Violin Concerto (Example 1) offers a fair example of this diversity: no pc is repeated in its seven notes. The bass line of Example 2 has pc 
repetitions, but they are considerably spread out, as demonstrated by the analysis below the music. Each horizontal line represents a non-duplicative pc succession within the bass line that begins and ends with the two pcs at the line's two endpoints. (Note that some of these successions begin with a pc that ends an earlier succession; to save space in these cases, lines representing such successions share endpoints.) These thirteen successions constitute the set of non-duplicative pc successions where no member of the set is completely embedded within any other: their average length is just under nine. ${ }^{7}$ Example 3 provides a similar analysis for a solo line from later in the concerto: the average length of the five successions is just over nine. Ideally, a thorough statistical analysis of this repertoire would confirm or correct this hypothesis; for now, a general familiarity with this music will need to suffice. This kind of pc diversity that characterizes Penderecki's overall melodic practice will be called 9-pc diversity: non-duplicative successions of either six or twelve notes are more rare than those of nine. However, it must be emphasized that the number of nine is merely a suggested average, not a necessary minimum nor a limiting maximum, for the lengths of Penderecki's non-duplicative pitch successions exhibit a substantial degree of variance around this mean.

Furthermore, this average may vary when one focuses on a particular piece or other smaller cross-section of this repertoire. For example, some of Penderecki's works, particularly from his early music, adopt twelve-tone serial techniques; therefore, one expects pc diversity to be higher when limiting one's scope to such pieces. However, in much of his music, many lines begin as if they might exhaust the aggregate, but then a non-trivial pc duplication occurs before all twelve pcs have been presented: examples abound in the Capriccio for Oboe and Strings (1964), Sonata for 'Cello and Orchestra (1964), Capriccio for Siegfried Palm (1968), Second String Quartet (1968) and others. Example 4 reprints a sampling of melodic runs from De natura sonoris No. 1(1966) that are highly representative of this time period. Although there are some non-duplicative successions of twelve notes among these runs, there are many more non-duplicative 
successions that fall short of twelve. This type of writing takes Penderecki farther away from the modernism of Vienna and Darmstadt and closer to the modernism of New England: Ruggles's pc diversity that falls short of consistent aggregate completion has been discussed ${ }^{8}$, and the same has been noted in Ives's music. 9 . The image of "broadbrush" ${ }^{10}$ strokes that Adrian Thomas uses to describe Penderecki's "sonorism" of the 1960s thus also serves as an appropriate metaphor for Penderecki's pc diversity: the composer's priority to cover all of - or enough of - the pitch-class aggregate with one coat of paint after another comes across clearly, even if some strokes overlap or he misses a couple of spots.

Along with 9-pc diversity, the other feature that characterizes Penderecki's melodies from his neo-Romantic period as well as from the earlier music of the 1960s and early 1970s is interval-class (ic) concentration. One does not need combinatorial analysis to understand that a relatively large sample of randomly generated melodies, with or without interior repetitions, will have a relatively flat distribution of the six nonzero unordered pc intervals (i.e. interval classes) between adjacent notes. The only bias would be a reduction of the number of tritones (ic6) by one-half, since this interval class only contains one ordered pc interval. Compared with this flat distribution, a great majority of Penderecki's melodies noticeably concentrate on two or three interval classes, although the degree of this concentration and the interval classes that are concentrated upon vary among pieces and stylistic periods. The semitone unquestionably serves as the fundamental building block of all of Penderecki's melodic motions, but the melodic interval classes that relieve the semitonal motion change from the sonoristic period to the neo-Romantic period. Before the mid-70s, most of his melodies weight the minor third and (somewhat less so) the major second considerably more than the major third, perfect fourth, and (somewhat less so) the tritone. The melodic runs in Example 4 from $D e$ natura sonoris display intervallic preferences very typical of the melodies from the $60 \mathrm{~s}$ and early 70s. This bias is also reflected in most of Penderecki's serial music: the twelve- 
Murphy, Scott. "A Model of Melodic Expectation in Some Neo-Romantic Music of Penderecki," Perspectives of New Music 25/1 (Winter 2007 ): 6-42.

Publisher's Official Version: http://www.perspectivesofnewmusic.org/. Open Access version: http://kuscholarworks.ku.edu/dspace/.

tone rows from Psalms of David (1958), Dimensions of Time and Silence (1960), and the St. Luke Passion (1966) focus almost entirely on the "small" interval classes of 1, 2, and $3^{11}$

With the arrival of Penderecki's neo-Romantic period, however, ic concentration becomes even more distinctive: his melodies now strongly gravitate toward the semitone and the tritone interval classes, or what will be called ic1/6 concentration. Adrian Thomas hears ic $1 / 6$ concentration as a hallmark of this period, beginning with the Violin Concerto: "While retaining some earlier methods, the concerto marks out future territory in its discursive, narrative structure and in its focus on two intervals, the semitone and tritone. The semitone has been the unmistakable cornerstone of Penderecki's vocabulary throughout his career, and unresolved chains of semitones, commonly separated by a tritone, have been the most conspicuous aspect of his melodic style since the mid1970s."12 The excerpts from the Violin Concerto discussed thus far exemplify this practice: the melodies in Examples 1 and 2 use semitones and tritones exclusively, and the melody of Example 3 intersperses a single minor seventh. Wolfram Schwinger notes that, by the Te Deum of 1980, "Penderecki was by now expert in the construction of melodies based on small intervals, particularly the minor second and the augmented fourth (the tritone)." ${ }^{13}$ Of course, the melodies of Examples 1 and 2, and even that of Example 3, are textbook examples; Penderecki does not exclusively use ic1/6 concentration in constructing all of his neo-Romantic melodies - the minor third and major second still make a fair number of appearances - just as all of Penderecki's melodies do not exclusively present nine pcs before repeating one of them.

Ray Robinson, in pinning down Penderecki's general stylistic traits that transcend particular style periods, claims that this mutual preference for semitones and tritones holds throughout his career. ${ }^{14}$ This study refines this claim by asserting that Penderecki's melodic use of ic $1 / 6$ concentration began sporadically and gradually increased during the sixteen years prior to the Violin Concerto, only to emerge as dominant with the beginning 
of the neo-Romantic period. During the 1960s, Penderecki's melodic lines generally do not spotlight the tritone any more than the other four non-semitonal interval classes, particularly the minor third. In the early 1970s, works such as the First Symphony (1973) and the Magnificat (1974) include extended melodic passages featuring ic1/6 concentration, although these are partially eclipsed by the numerous other passages that do not. Moreover, some of the few exceptions to this gradual process are programmatically motivated: for example, the tritone finds its way into many of the melodic lines in Dies Irae (1967). Ic1/6 concentration also plays a dramatic role in Penderecki's first opera The Devils of Loudon (1969): one of the clearest examples is provided in Example 5, which sets a text whose English translation is "the blood that will flow between us will make us one."

Thus, what sets the use of ic $1 / 6$ concentration in early neo-Romantic works like the Violin Concerto and Paradise Lost apart from its use in these earlier instances is that, like 9-pc diversity, it permeates the entire work as a melodic modus operandi. This also sets the early neo-Romantic works apart from more recent music. Although Thomas is correct that ic $1 / 6$ concentration has been "the most conspicuous aspect of his melodic style since the mid-1970s," it is certainly does not overwhelmingly dominate the melodic writing in most of the music from 1980 on as it does in the Violin Concerto and Paradise Lost. Rather, it becomes one stylistic thread that the composer weaves into a new compositional fabric, much as the avant-garde techniques that dominated the music of the early 60s became woven into the "synthetic" music that followed. Yet this feature of ic 1/6 concentration, coupled with 9-pc diversity, is still Penderecki's most distinctive melodic fingerprint, even if it is but one of many stylistic marks presented by a work's melodic content. Therefore, in a piece like his Capriccio for Tuba Solo (1980), where the abundant motivic repetition, scherzo and waltz rhythms, and significant octatonicism might make it difficult for even connoisseurs of twentieth-century art music unfamiliar 
with this music to name its composer, the few passages that unambiguously project 9-pc diversity and ic1/6 concentration disclose Penderecki's identity.

\section{MELODiC EXPECTATIONS AND TONAL ANALOGIES}

Penderecki's consistent use of 9-pc diversity and ic1/6 concentration, whether in entire works like the Violin Concerto or Paradise Lost or in isolated passages from earlier or later works, not only signifies a particular melodic style, but it also affords someone familiar with the style the ability to make reasonable predictions about how some of these melodies might continue. For example, given a six-note melodic incipit CB-F-E-D\#-A in the context of Penderecki's neo-Romantic style, the claim of ic1/6 concentration predicts that $\mathrm{D} \sharp, \mathrm{G} \#$, or $A \sharp$ will probably follow, since these are the three pcs that ensue when adding the intervals of a tritone, a descending semitone, and an ascending semitone respectively to the final note A. These kinds of predictions give rise to what will be called ic1/6 expectations. Alternatively, the claim of 9-pc diversity predicts that one of the six other pcs that has not yet been stated $\{C \sharp, D, F \sharp, G, G \sharp, A \sharp\}$ will probably follow. Admittedly, there is also a fair but presumably smaller chance that a $\mathrm{C}$ will follow, since $\mathrm{C}$ occurred first in the melody, whereas the odds of $\mathrm{D} \#$ coming next are much more slim (unless it is commencing an interior repetition). As mentioned earlier, the nine-note average is far from a precise limit of pc diversity, and to use it as such would be misconstruing Penderecki's melodic style. However, without more precise statistical information, the predictions based on 9-pc diversity are reluctantly but necessarily simplified by 1) restricting their application to pc successions no more than eight pcs long, and 2) only predicting pcs that have not been stated within such successions. These kinds of predictions give rise to what will be called 9-pc expectations. The stylistically informed person bringing these two sets of expectations to a melody in medias res could be the composer himself deciding what note to write next, or it could be 
a performer or an expert listener anticipating the next pitch. The monophonic and unhurried melodic presentations that occasionally turn up in Penderecki's neo-Romantic music make this last scenario far more feasible.

As discussed at the outset, although Penderecki revisits many aspects of the nineteenth-century style in his neo-Romantic music, he slights common-practice tonality by not meeting a great majority of the expectations brought by a tonal ear. Therefore, what remains untapped in Penderecki's music are familiar experiences like the relative tension inherent in a dominant triad or the stability of a tonic triad, the surprise wrought by an unexpected harmonic progression or the satisfactory conclusion offered by a familiar cadence. One could interpret their absence as the composer's deliberate restraint from stylistically regressing any further. However, a consistent employment of 9-pc diversity and ic $1 / 6$ concentration, while not creating expectations that imitate those of tonality, nonetheless may create expectations specifically within the domain of pitch class that are analogous to, and potentially standing in for, those of tonality, facilitating a communication of familiar messages to the performer, listener, and analyst through a new "modernist" medium.

However, the familiar tonal messages that will be analogized in this study do not emanate from what conventional wisdom deems as particularly "rich" models of tonality, such as Heinrich Schenker's, but rather from admittedly simplified models of tonality: local event-to-event expectations of diatonic harmonies as they have been codified by prose and/or flowcharts in textbook introductions to tonal harmony, or by more recent quantitative measures. ${ }^{15}$ One may first question how analogizing such a rudimentary set of expectations with Penderecki's neo-Romantic music adequately captures the richness of the latter. In one sense, it inherently does not, in that these tonal harmonic expectations are limited to a single parameter — pitch class — and to "Markov first-order" probabilities. But, in other sense, such expectations achieve an appreciably high degree of complexity within these limits, as demonstrated by four basic conditions shared by most models of 
basic diatonic harmonic expectations. To illustrate these conditions, Example 6 employs graphs that depict an abstract element's expectancy profile. The horizontal axis arranges all the possible continuations of the element partially ordered from high to low by the degrees to which these continuations are expected, shown on the vertical axis. The following four conditions should be met by any set of expectations proposed as analogous to a textbook model of diatonic harmonic progression:

1. The "dominant" condition: there is at least one highly determinate element that has a single most probable and strongly expected continuation. A fundamental aspect of tonal harmonic syntax is that one firmly expects dominant harmony to be followed by tonic harmony. Dominant harmony is therefore analogous to any element whose number of likely continuations is, for all practical purposes, narrowed to one. Example 6a represents the dominant condition with a single spike for the sole highly determinate continuation.

2. The "tonic" condition: there is at least one highly indeterminate element where all of its continuations are expected to more or less the same degree. Kostka and Payne purport that "any chord may follow" tonic harmony. ${ }^{16}$ This results in a flat expectancy profile for the tonic triad as shown in Example 6b, which means, somewhat paradoxically, that all continuations are equally expected and that no continuation is particularly expected. These dual interpretations befit the two customary formal positions of tonic: since tonic is the least partial regarding what in particular comes next, a formal unit that opens with tonic is full of possibilities; and since tonic is the least frustrated when nothing in general comes next, a formal unit that ends with tonic is an appropriate conclusion. Tonic harmony is therefore analogous to any element whose number of most likely continuations is the maximum number or, by the same token, zero.

\section{The communal gradation condition: the set of elements enjoys a variance} among the degrees to which elements resemble dominant or tonic elements. These definitions of tonic and dominant elements are idealized categories, existing as two poles 
of a continuum of expectancy profiles whose length is measured by the number of most probable continuations: from one at the dominant pole, to all (or, equivalently, none) at the tonic pole. It is significant that the expectations of tonal harmony do not cluster toward one end of the continuum or the other, resulting in either an overly deterministic system where every harmony has a singular most probable continuation, or an overly chaotic system where any harmony could proceed to any other. Rather, many expectancy profiles of tonal harmony fall in between these two extremes. For example, the II chord, as a pre-dominant harmony, is largely a "dominant" element as more broadly defined here, in that its expectancy profile is more honed. However, since most textbook models bundle the dominant and leading tone harmonies together into a dominant function, the focus of pre-dominant harmonies is not quite as sharp as that of dominant harmony, resulting in something more like the shaded graph of Example 6c than the graph of Example 6a. Furthermore, the mediant and submediant triads come closer to the tonic pole: according to Robert Gauldin, they are "less focused and more variable"17 in what harmony is expected to follow, and better symbolized by the non-shaded graph of Example 6c. Ultimately, this continuum permits any element on it to be described relative to another element: one as more determinate and one as more indeterminate; graphically, one as a steeper stair-step and one as a gentler stair-step; analogously, one as "more dominant" and one as "more tonic."

\section{The individual gradation condition: most elements, besides completely tonic} elements, enjoy a variance among the degrees of expectation for each of the elements that are likely to follow it. As the communal gradation condition makes fuzzy the crisp distinction between dominant and tonic categories, this condition makes fuzzy the crisp distinction between completely expected and completely unexpected. In other words, this condition prefers those expectancy profiles with more stair steps. For example, Walter Piston's classic summaries of normative harmonic progressions such as "IV is followed by V, sometimes I or II, less often III or VI" succinctly capture this concept of individual 
gradation that most would ascribe to non-tonic tonal harmonies. ${ }^{18}$ The shaded graph of Example 6d offers a simple example of a profile that better meets this condition than those of Examples 6a and 6c. These intermediate degrees of expectation permit a qualitative range in how certain continuations may be interpreted: compare the "deceptive" near miss of V $\rightarrow$ VI with the "retrogressive" contravention of V $\rightarrow$ IV.

How well do the two sets of expectations associated with Penderecki's neoRomantic melodic style measure up as analogous to tonal expectations according to these four conditions? The set of ic1/6 expectations, applied to any set of melodies, baldly fails to meet any of them. All melodies have the same expectancy profile: a binary delineation between the three pcs that are each equally probable to follow, and the nine pcs are that each equally probable not to follow. The number of expected pcs is too high to meet condition \#1, too low to meet condition \#2, and too fixed to meet condition \#3; and the binary segregation fails condition \#4. Therefore, although ic1/6 expectations embrace neither complete determinism nor complete chaos, they also completely eschew any singular instance of these two states, producing a rather humdrum experience as measured by these four conditions.

The set of 9-pc expectations, applied to the set of non-duplicative melodies that do not exceed eight notes, fares only slightly better. A melody of a single note amply meets the tonic condition, since any one of the other eleven pcs have an equal chance of following. This makes formal sense in the analogy with tonality: pc diversity associates every beginning of a Penderecki melody with tonic and its potential to head in the highest number of directions. However, this "degree of tonicity," as measured by the number of probable continuations, never returns anywhere near this high again to conclude (as proper with the tonal analogy) a longer melody, for as a melody adds note after note, the number of probable continuations, and thus its association with tonic, steadily and inexorably decreases. This evinces a communal gradation, but one distinguished only by the melody's length, not by its content. In other words, two melodies of equal length will 
have the same expectancy profile-hardly a nuanced model of melodic expectation.

Furthermore, a melody's most probable continuations are equally probable, undermining individual gradation. 9-pc diversity fails the dominant condition outright: there is no melody where a single pc continuation predicted by 9-pc diversity clearly sticks out as more probable than the others.

In light of these disappointments, perhaps a model for melodic expectation in Penderecki's neo-Romantic music should be based on observations more detailed than these two relatively simple summations of the composer's melodic style as provided by existing scholarship. For example, ic1/6 expectations could be fine-tuned to accommodate the observed tendency for tritone leaps to occur less often than semitonal intervals, or the observed tendency for a tritone leap to be followed by the ordered pc interval that preceded it. Or the two simplifications earlier imposed on 9-pc diversity could be lifted: certainly this would effect an individual gradation, particularly for longer melodies, as pcs stated six to eight notes earlier would be expected more than those stated more recently, but less than those not stated yet. However, there is no immediate need for this, for a model that comes much closer to an analogy to tonal expectations as embodied in the proposed four conditions can be simply and elegantly achieved by considering the sets of 9-pc expectations and ic $1 / 6$ expectations working in tandem. That is, a pc is expected to follow a melody only if it meets both 9-pc expectations and ic 1/6 expectations. The first and most obvious product of their collaboration is the demotion of one of the probable continuations of a melody as predicted by ic concentration: namely, the melody’s penultimate note. In the case of C-B-F-E-D $\#-A$, although ic1/6 concentration expects $\mathrm{D} \#$ to the same degree as $\mathrm{G} \#$ and $A \#, 9-p c$ diversity does not expect $\mathrm{D} \#$ at all, since it was just presented. Thus, the combination of these two features leaves only two pcs, $\mathrm{G} \#$ and $\mathrm{A} \#$, as the two equally probable continuations. However, this collaboration does not seem to affect communal variance: all melodies, save those singletons without a penultimate note, would experience this same reduction and be left 
with two equally probable continuations. Yet, this is not always the case. While many melodies have exactly two continuations that meet both criteria, some melodies have exactly one - thus fulfilling the dominant condition - and a few have none - thus fulfilling the tonic condition. This creates a threefold communal gradation that holds even among melodies of the same length, as shown in the following analyses.

\section{ANALYSES}

Wolfram Schwinger's examination on the opening of the Violin Concerto (Example 1) is as follows: "The second group of cellos gives out the first thematic line (bar 6), a chromatic cantabile theme, rising and falling with a tritone leap A flat-D in the middle. This is a brooding theme. Cellos repeat it, a tone higher and without its last note, whereupon violins (at bars 9 and 10) keep the notes but change the rhythm in the metamorphosis, central to the character of this work." Example 7a lays out the pcs of Schwinger's "cantabile theme”: F $\sharp-G-A b-D-D b-C-B$. The number above each pc is the number of pcs, as allowed by 9-pc diversity and ic1/6 concentration, that may immediately follow the melody at that point, and the tree graph that grows down from the pc sequence indicates the immediate pc continuations not chosen. After the three-way option following the first note, the melody entertains two probable continuations for its second through fourth notes: $\mathrm{G}$ could continue to $\mathrm{A} b$ or $\mathrm{D} b, \mathrm{~A} b$ could continue to $\mathrm{D}$ or $\mathrm{A}$, and $\mathrm{D}$ could continue to $\mathrm{D} b$ or $\mathrm{E} b$. However, when the melody executes the switchback to $\mathrm{D} b$, the ground covered earlier greatly decreases the possibility that a tritone leap will follow the $\mathrm{D} b$ or $\mathrm{C}$, as this would duplicate a pc already used. The melody therefore has but one probable pc continuation from the $\mathrm{D} b$ to the $\mathrm{C}$, and from the $\mathrm{C}$ to the $\mathrm{B}$, "locking" it into a semitonal descent. However, when the melody arrives at and finishes with the note $\mathrm{B}$, two probable continuations once again avail, returning to the ambivalence presented earlier in the melody. The progression from two probable continuations for the 
beginning, down to one for the middle, then back up to two for the end creates a less determinate-more determinate-less determinate succession that is analogous with $\mathrm{I}-\mathrm{V}-\mathrm{I}$, or, at the least, a "more tonic"-“more dominant"-"more tonic" progression using the broader definitions of these terms introduced earlier.

Recall that Schwinger takes care to notice that the statement of the cantabile theme up a half step in mm. 8-9-G-G\#-A-Eb-D-Db-is “without its last note.” This pc sequence is analyzed in Example 7b. This seemingly unremarkable omission eliminates a resolution to the final I of the cantabile theme's I-V-I progression, creating an ending analogous to a half cadence: there is one continuation, far and above the others, that is most expected to come next, yet the melody concludes nevertheless. Furthermore, the endings of these three melodic statements - the cantabile theme in mm. 6-7, its trimmed version in $\mathrm{mm} .8-9$, and its full restatement in $\mathrm{mm} .9-10$ - realize the $\mathrm{I}-\mathrm{V}-\mathrm{I}$ progression of the cantabile theme on a larger scale.

Therefore, although the B naturals are tonally determinate regarding pc expectations generated by an F-minor perspective as discussed earlier, they offer the opposite effect regarding expectations generated by the combination of Penderecki's two idiosyncratic melodic features. An inverted situation regarding the play between tonal expectations and the expectations generated by Penderecki's two melodic features occurs right before the soloist's first entrance. The slow introduction gives way to a poco più mosso section that builds in volume and textural density for twelve measures to a climax, followed by a return to the slow introduction's F bass pedal and a simpler texture. Example 8 displays the music that brings the "orchestral exposition" to a close. The most two prominent melodies here are a mezzo forte viola line in seven notes and a piano bass clarinet line that descends by semitones with a single interior repetition. The two lines form a chromatic 7-6 suspension chain, then the violas leap into a $C \sharp$ dissonant against the bass clarinet B bass pedal, then resolve it to D. This faint but sustained minor-third consonance ushers in the soloist. However, from the perspective of expectations 
generated by Penderecki's two melodic features, the viola's D is relatively determined and thus "unstable." As shown in Example 9, all of the pitches leading up to the D have two probable continuations; however, the $\mathrm{D}$ can only continue to $\mathrm{D} \sharp$ and stay true to both melodic features. As proposed earlier, a melody with a single most probable continuation is analogous to dominant. Thus, according to 9-pc and ic1/6 expectations, the viola's melody ending the orchestral exposition strongly anticipates a $\mathrm{D} \#$, in contrast to the slow introduction that concluded with less anticipation. And indeed, the soloist begins with the anticipated $\mathrm{D} \#$, but only after a pregnant pause.

A return to Example 3 provides an attractive example of an incipit in the concerto that has no probable continuations at all - what will be called a terminal melody. Here, the seven notes $\mathrm{B} b$-A-Eb-D-Db-G-Ab begin a melodic passage in the solo violin accompanied by faster and slower melodies in the orchestral strings. As shown in Example 10, this seven-note incipit paints itself into a corner, to reuse an earlier metaphor. A continuation that honored ic1/6 concentration would reuse a pc $(\mathrm{G}, \mathrm{A}$, or $\mathrm{D})$, and a continuation that honored 9-pc diversity would engage an interval outside of interval class 1 and 6 (ics 2, 3, or 4). Therefore, in considering the expectations of both features, there are no pc continuations that are especially anticipated, making the $\mathrm{Ab}$ that ends this seven-note succession strongly analogous with tonic. Or, to put it another way, all eight pc continuations - the five pcs predicted by 9-pc diversity $\{\mathrm{C}, \mathrm{E}, \mathrm{F}, \mathrm{F} \#, \mathrm{~B}\}$ and the three pcs predicted by ic $1 / 6$ concentration $\{\mathrm{D}, \mathrm{G}, \mathrm{A}\}$-are more or less equally probable. To follow the incipit with more material, Penderecki must violate one of the two features. In the excerpt of Example 3, he violates ic1/6 concentration by ascending a minor seventh to $\mathrm{G} b$, and then continues a strict maintenance of pc diversity and ic $1 / 6$ concentration up to the E natural.

However, unlike the lingering Bs in the opening of the concerto, Penderecki does nothing else to articulate the "tonicity" of the Ab in this Vivo passage beyond the change of bow. Yet later in the concerto, Penderecki brings back this material at a softer dynamic 
and a slower tempo. The concerto boasts three cadenzas, of which the opening of the third and last (m. 563) is shown in Example 11. He begins with the same seven-note incipit, but this time, the $A b$ is followed by a caesura (as is the E when Penderecki starts over and runs through the first ten notes). The slower tempo and monophonic texture may afford an opportunity for an expert listener familiar with Penderecki’s melodic style to project an ascending semitone, a descending semitone, and a tritone from this lingering $\mathrm{A} b$, and to recognize that all three resultant pcs have already been presented. ${ }^{19}$ To call the music "stuck" at this point is a bit excessive - it has already been emphasized how these features are not totally binding - but to say that this incipit offers relatively little bias about what will follow next is appropriate. Therefore, from this point of view, it makes sense to synchronize the caesura with the "tonic" quality of this specific moment: nothing in particular is strongly expected to follow.

Another example where the end of a terminal melody coincides with a conclusion articulated by one or more other components is the excerpt from The Devils of Loudon introduced earlier (Example 5), a ten-pitch melody that adheres strictly to 9-pc diversity and ic1/6 concentration. Example 12 provides an analysis, showing that any eleventh pitch must violate one of these two features. This point of least relative certainty in what pc will follow - again, what has been analogized with the tonic scale degreeaccompanies the end of the sentence and Jeanne's melodic line. One might contest that, as stated earlier, 9-pc expectations are applicable only to pc successions no longer than eight notes, and this ten-note melody clearly exceeds this mark. However, the analytical subject need not be the entire ten-note melody, but merely the last six notes, since all the probable ic $1 / 6$ continuations $-E b, A b$, and $\mathrm{B} b$-occur within this final span. 


\section{THE PENDERECKI TREE}

The above examples provide a few instances of communal gradation among the expectations of melodies, even among melodies of the same length, when the features of 9-pc diversity and ic1/6 concentration are considered in tandem. But does this variety permeate the expectations generated by all possible melodies that adhere to Penderecki's melodic practice? The process of answering this question can begin by enumerating the set of non-duplicative melodies that use only ordered pc intervals 1 (ascending semitone), 6 (tritone), and e (descending semitone): what will be called Penderecki melodies that form the Penderecki set. Since transposition and/or inversion do not change a melody's expectancy profile, the Penderecki set may be partitioned into melody-classes equivalent under these canonic operations. However, rather than present the Penderecki set first in tabular form, the set may instead assume a more compact form that has already been adopted on a small scale so far. An extension of any one of the trees in the analyses of Examples 7, 9, 10, or 12 to show all of the Penderecki melodies that began with the same pc would result in a tree isomorphic to Example 13 , the Penderecki tree. ${ }^{20}$ As in the trees of the earlier analyses, the vertices represent pcs, the edges represent intervals 1,6 , and e, and every left-to-right path through the tree represents a single Penderecki melody. However, in the Penderecki tree, every left-to-right path that begins with the tree's "root" - the leftmost, zero vertex — corresponds bijectively with a Penderecki melodyclass. Therefore, each of the 283 vertices of the Penderecki tree represents (as its terminus) a melody-class, and the number of vertices in each column represents the number of equivalence classes of a particular cardinality. Because of its size, the tree has been divided over two pages: the first page presents the half-step (HS) branch, which indicates all melody-classes that begin with a half step, and the second page presents the tritone (TT) branch, which indicates all melody-classes that begin with a tritone. 
Transpositional and inversional equivalences allow for a number of simplifications of the Penderecki tree. First, the root can be any pc and the tree would look exactly the same: consider the arbitrary choice of 0 as the root as putting the Penderecki tree in "normal form." Second, the part of the tree that continues a descending-semitone two-note incipit is an exact inversion of the part of the tree that continues the ascending-semitone two-note incipit; this is annotated with the words “inverse of $01 \ldots$..." Likewise, the part of the tree that continues a $<6 \mathrm{e}>$ three-note incipit is an exact inversion of the part of the tree that continues a $<61>$ three-note incipit; this is annotated with the words "inverse of $061 \ldots$ " on the TT branch. To save space, these two parts of the tree have been pruned. Transposing and/or inverting a melody so that it begins with 012,017 , or 067 is to put the melody in "prime form." For example, the prime form of the melody $\mathrm{B} b-\mathrm{A}-\mathrm{E} b-\mathrm{D}-\mathrm{C} \sharp-\mathrm{G}-\mathrm{A} b$ from Examples 3 and 11 is 0178932 . As one traces the pitches of the prime form through the tree, the number of right branches from each vertex in the melody represents the number of pc continuations from that particular point. Prime form 0178932 (and thus all Penderecki melodies in the same melody class) enjoys binary branching until the last note, which rests on a terminal vertex, symbolized by the vertex's octagonal shape.

Since Penderecki employs 9-pc diversity instead of 12-pc diversity, his melodies rarely climb near to the "top" of the tree. The simplification of 9-pc expectations invoked earlier is represented by the dotted vertical line that indicates the point farthest from the tree's root at which melodies are less likely to cross than not. Therefore, among the 283 melody classes, the 111 melody classes that are longer than one note and shorter than nine notes are of primary analytical concern. These 111 melody classes are tabulated in the Appendix. Following Allen Forte's nomenclature for unordered set classes, each melody class is assigned a two-number label (abbreviated LB in the Appendix) and a prime form (PF) in the two leftmost columns. ${ }^{21}$ For example, Bb-A-Eb-D-C $\sharp-G-A b$ is a member of class 7-15 with a prime form of [0178932]. This two-number label can be 
identified on the tree with little trouble: the final vertex of this melody is in the seventh column from the left, and the fifteenth vertex from the top in this column. (Since the tree is divided into two parts, one must remember to start on the first page when counting from the top down.) In the next column of the table, each prime form is also characterized by its series of intervals between adjacent pcs, what Robert Morris calls $\mathrm{INT}_{1}$, simplified to INT. ${ }^{22}$ The next column provides the number of most probable pc continuations for every melody class. The remaining columns will be discussed shortly.

Although the Penderecki tree maintains some structural redundancies beyond the two aforementioned that were pruned,,$^{23}$ these are overshadowed by the tree's asymmetric complexity, an overall testament to the synergistic union of the two relatively simple melodic features of pc-diversity and ic1/6 concentration. The table also facilitates an analysis of these tandem expectations according to the four conditions outlined earlier. The Appendix column entitled "\# PC CONT" displays the number of most probable pc continuations of a melody in a melody class. Setting the three continuations of the root aside, this column reveals a three-tiered communal gradation that cuts across the cardinality classes: six melody classes are terminal with zero continuations ("most tonic"), forty melody classes have one continuation ("most dominant"), and the remaining sixty-five melody classes with two continuations fall in between the "most tonic" and "most dominant" poles on the communal-gradation continuum. It is curious that, among these 111 melody classes, the six terminal melody classes -6-16, 7-15, 8-10, $8-25,8-34$, and $8-41$ - are by far the most rare. In other words that continue the paintbrush analogy, there are very few ways the composer can paint himself into a corner so "quickly" that the wet surface truly pins one in. Three of these six terminal melodyclasses $-7-15,8-10$, and 8-41 - end with melody-class 6-16; this can be seen by finding 6-16's interval series of $<6116 \mathrm{e}>$ at the end of each of their interval series. This promotes 6-16 to an extremely special and nearly singular status among these 111 melody classes, not completely unlike the singular status tonic harmony has among the seven diatonic 
Murphy, Scott. "A Model of Melodic Expectation in Some Neo-Romantic Music of Penderecki," Perspectives of New Music 25/1 (Winter 2007 ): 6-42.

Stufen. The melodies from Examples 5 and 11, which terminated with textual punctuation and a caesura respectively, both end with 6-16.

To reiterate, the general heterogeneity and asymmetry of the Penderecki tree correlates with the general heterogeneity and asymmetry of tonal expectations, and the model of expectations that combines 9-pc diversity and ic $1 / 6$ concentration meets the first three proposed conditions deemed necessary to be analogous with a tonal model. What of the fourth condition, that of individual gradation? Regardless of whether the model generates an expectation of zero, one, or two pcs, there is still a binary distinction between those pcs that are expected and those that are not. One could differentiate among those in the latter group by, for example, claiming that pcs generated by either 9-pc or ic $1 / 6$ expectations are more expected than those generated by neither. For example, in the case of the previously discussed incipit of C-B-F-E-D\#-A, this would assign $\mathrm{G} \#$ and $A \sharp$ as the most probable continuations, the $\mathrm{D} \#, C \sharp, D, F \sharp$, and $G$ as less probable continuations, and the C, E, F, and B as even less probable. One could also refine this simplified version of 9-pc diversity by incorporating a probability distribution around the mean of nine that reflects a more thorough statistical analysis of the frequency of certain lengths of nonduplicative pc successions. At the least, this would reflect Penderecki's melodic practice by considerably reducing the expectation of the penultimate $\mathrm{D} \#$.

However, a focus on a differentiation among those that are the most expected is closer to the priorities of tonal expectancy models. Such models, such as those of diatonic harmony presented in introductory textbooks, do not fret over the comparison of highly anomalous situations, such as whether a IV chord or II chord is more expected to follow a V chord. Rather, they sift through the "high end," teasing apart the degrees of expectations for normative $\mathrm{V} \rightarrow \mathrm{I}$ progressions versus deceptive $\mathrm{V} \rightarrow \mathrm{VI}$ progressions, or predominant IV $\rightarrow \mathrm{V}$ progressions versus plagal IV $\rightarrow$ I progressions. In the case of Penderecki's tandem melodic expectations, a "high end" suitable for teasing apart is when a melody has two equally possible pc continuations, such as the $\mathrm{G} \#$ and $\mathrm{A} \sharp$ for $\mathrm{C}$-B- 
Murphy, Scott. "A Model of Melodic Expectation in Some Neo-Romantic Music of Penderecki," Perspectives of New Music 25/1 (Winter 2007 ): 6-42.

F-E-D\#-A. What could make one of these pcs more expected than the other? Since a seven-note melody falls short of the nine-note average of Penderecki's pc diversity, it is assumed, in the absence of contrary information, that after either the $G \sharp$ or $A \sharp$ comes next, the melody will continue to observe both 9-pc diversity and ic $1 / 6$ concentration for at most two more notes. From this point of view, the continuations to $G \#$ and $A \sharp$ are very different. If the $\mathrm{G} \#$ comes next, there are five more ways to press on toward an eight- or nine-note well-formed melody. Yet, if the $A \sharp$ comes next, the seven-note melody is thereby terminal: no probable continuations are available. This can be seen easily enough on the Penderecki tree: the 3 that concludes the prime form path [017893] is followed by two branches, yet the branch with six vertices is considerably "heavier" than the branch with one vertex.

The three rightmost columns in the table located in the Appendix deal with this kind of bias for melodies. The column labeled "\# MEL CONT" shows for a given melody the number of longer melodies, up to a length of nine, that the given melody begins. For $\mathrm{C}-\mathrm{B}-\mathrm{F}-\mathrm{E}-\mathrm{D} \#-\mathrm{A}$, which is in melody-class 6-9, there are seven such longer melodies. The left column under the "BIAS" heading partitions a non-zero number of longer melodic continuations into one or two subsets, parenthetically identified by the melody-class one note longer that begins each of the longer melodic continuations in the subset. For example, for a melody in class $6-9$, these seven options for continuation are partitioned into the six that begin with melodies in class 7-14 and the one that begins with a melody in - or, in this case, belongs to-class 7-15. The final column expresses the discrepancy between the size of the subsets as 1 - (the size of the smaller subset / the size of the larger subset). Thus, all values will be between 0 and 1 , where 0 represents a melody that is completely unbiased, 1 represents a melody that has a single most probable continuation, and the numbers in between flesh out the continuum between no bias and complete bias between two possible pc continuations. In the case of a melody in class 6-9, the size of the smaller subset is 1 , and the size of the larger subset is 6 ; therefore, the value is $1-$ 
$(1 / 6)$ or .83 . This relatively high number represents the relatively strong expectation that one pc will follow compared to the next most likely. The continuum from 0 to 1 now correlates exactly with the continuum from "most tonic" to "most dominant," since terminal melodies are also assigned a value of zero.

These biases provide a higher-resolution picture of the moment-to-moment expectations in the previously analyzed melodies. Example 14 revisits the "cantabile theme" from the opening of the Violin Concerto, where the label above a certain point in the melody indicates the melody-class to which the succession up to that point belongs, and the value between 0 and 1 below this point indicates the bias of this melody-class. The graph below charts the change of bias from "most tonic" (0) to "most dominant" (1). The melody starts "on tonic" with negligible bias, then the bias increases significantly with the leap to the D, forming melody class 4-2. Consulting the table in the Appendix, melody-class 4-2's fairly strong expectation (.53) is to be extended with an ascending semitone to melody-class 5-3, since it begins just over twice as many longer melodies between five and nine notes as melody class 5-4 does. However, the "cantabile theme" descends a semitone, taking the path less expected. This demonstrates how this expectancy model accounts for the earlier observation of the tendency in Penderecki's melodies for a tritone leap to be followed by the ordered pc interval that preceded it. The bias numbers basically predict this phenomenon: no melody-class with 2 pc continuations whose INT ends with $<x, 6>$ has a biased preference for a melody-class whose INT ends with $<\mathrm{x}, 6,-\mathrm{x}>$. After its channeled continuations to $\mathrm{C}$ and $\mathrm{B}$ that fully invoke the determinism of dominant, the melody rests on $\mathrm{B}$, which is not completely tonic (.33), but offers the closest value to tonic since the beginning of the melody.

Example 15 revisits the caesura-interrupted opening of the final cadenza. This seven-note succession stays relatively close to tonic; the small bias at the $\mathrm{Eb}$ (.38) is for the following $\mathrm{D}$, which is also predicted by the fact that the tritone leap was preceded by a descending semitone. In fact, each point in this melody continues with the predicted pc 
through the penultimate $\mathrm{G}$, where the bias becomes much higher between the expected continuation to the open-ended $F \#$ and the unexpected continuation to the terminal $A b$. This bias provides a strong dominant-like expectation that leads to tonic when the melody becomes "stuck" on the Ab, a dramatic change in bias analogous to an authentic cadence that was not apparent in the analysis of Example 10. Of course, this is one of multiple places where the analogy falls short: although two successive moments in a melody can be analogous to dominant and tonic because of their degree of determinism, the pc highly expected at the dominant moment is not necessarily the one that creates the succeeding tonic moment. In this model, dominant and tonic are not entities per se, but states of expectation.

One final observation: of all the possible interval classes that can be paired with Penderecki's ubiquitous interval class 1, this one-dimensional continuum between tonic and dominant is only possible by combining the half step with the neo-Romantic interval class 6 . Since the tritone inverts into itself, ic $1 / 6$ concentration avails only three ordered pc intervals, and, after the first melodic interval, pc diversity limits the number of possible pc continuations to two, since an interval followed by its inverse would result in premature pc duplication. Therefore, with the exception of the ternary branching from the root, the Penderecki tree is (at most) binary, which affords the single dimension: "how strongly is the melody expected to go this way as opposed to that way?"

$* * *$

In Penderecki's neo-Romantic music, there are a few moments, in addition to those previously discussed, when a conclusion of a phrase or section as articulated by silence and/or a pronounced change in texture, instrumentation, dynamics, tempo, etc. coincides with either a terminal melody or, more generally, a melody ending "dominant to tonic." ${ }^{24}$ However, dwarfing this phenomenon is the much more frequent situation in 
this repertoire when the first means of articulating closure is not accompanied by the second, and vice versa. Since observations made by this expectancy model do not strongly correlate with an independent variable such as the music's formal division, the model does not support a general theory of closure in Penderecki's neo-Romantic music.

However, this failure does not discount entirely, or even significantly, the utility of the model presented herein. While the model may not be able to predict whether a point in a melody in this particular repertoire is the melody's conclusion, it generally succeeds at predicting what pc will come next (if indeed the melody continues) at those moments when the bias is high. So, whereas tonal pc expectations are largely left unrealized in this music, expectations generated by $9-p c$ diversity and ic $1 / 6$ concentration are much more profitable in their return of realizations. Furthermore, this set of expectations achieves an intricate balance between complete chance and complete determinism that has been shown to be a significant component of tonal expectations. Since Penderecki's neo-Romantic music co-opts conventional tonal syntax to much less of a degree than other aspects of common-practice music such as tertian harmonic language and traditional orchestration, this study encourages the hypothesis that the support of pc expectations generated by the proposed model stands in for a support of tonal pc expectations.

On the one hand, to argue that this music engages pc expectations that are analogous to tonal pc expectations might be understood as reinforcement of the view that Penderecki's move toward neo-Romanticism was truly a step backwards, a view shared by the composer himself. In his book, Labyrinth of Time: Five Addresses for the End of the Millennium, Penderecki uses the metaphor of a labyrinth to describe and defend his return to more traditional idioms. ${ }^{25}$ Speaking on behalf of artists at the end of the century, he states, "We find ourselves in a labyrinth. We start down many paths, we back up and return with a highly unclear sense of our objective." ${ }^{26}$ He then notes that the current condition of art "does indeed suggest a dead-end. In all domains of art, we can see how 
ideas and materials are being used up...We have reached a point where opening the door behind us is the summit of creativity." ${ }^{27}$ In another address, Penderecki's tone is more somber: "I cannot think of another period in the history of music as marked by decline as our own. No new paths of development can be seen. Artists are exploiting old ideas and turning back to the past." 28

On the other hand, unlike the literal return to common-practice features such as tertian harmonies and traditional orchestration, it has been proposed here that Penderecki's return to tonal pc expectations is analogical. Therefore, the "neo" in Penderecki's "neo-Romanticism” may signify more than Heraclitian anachronism and recontextualization. It may also signify a means of creating expectations that, while analogous to tonal expectations in their balance of chance and determinism, stem from the combination of two melodic characteristics that, prima facie, hardly support commonpractice tonality. Ic $1 / 6$ concentration employs the two rarest interval classes in the diatonic set, and 9-pc diversity offers one means, akin to Schoenberg's conception of the twelve-tone system, to avoid a bias toward a central pitch. ${ }^{29}$ As Mieczysl'aw Tomaszewski puts it, "Penderecki did not hide his enthusiasm for the nineteenth century. He believed that this thread which was cut short has enough vitality to be continued; of course it was to be done on another plane, in full awareness of what happened later. He said yes to the return of melody, but one which did not forget the purifying lesson given to it by dodecaphony and serialism. [emphasis mine]"30 The two spatial metaphors of Penderecki's labyrinth and Tomaszewski's plane fit well together. Penderecki may have retreated from the "dead end" in many obvious ways, but, in at least one subtle way, he accompanied this retreat with the discovery of a completely novel expression of a timehonored concept that lifted this "neo-Romantic" style to a new level, thus blazing a way up and out of the labyrinth. 

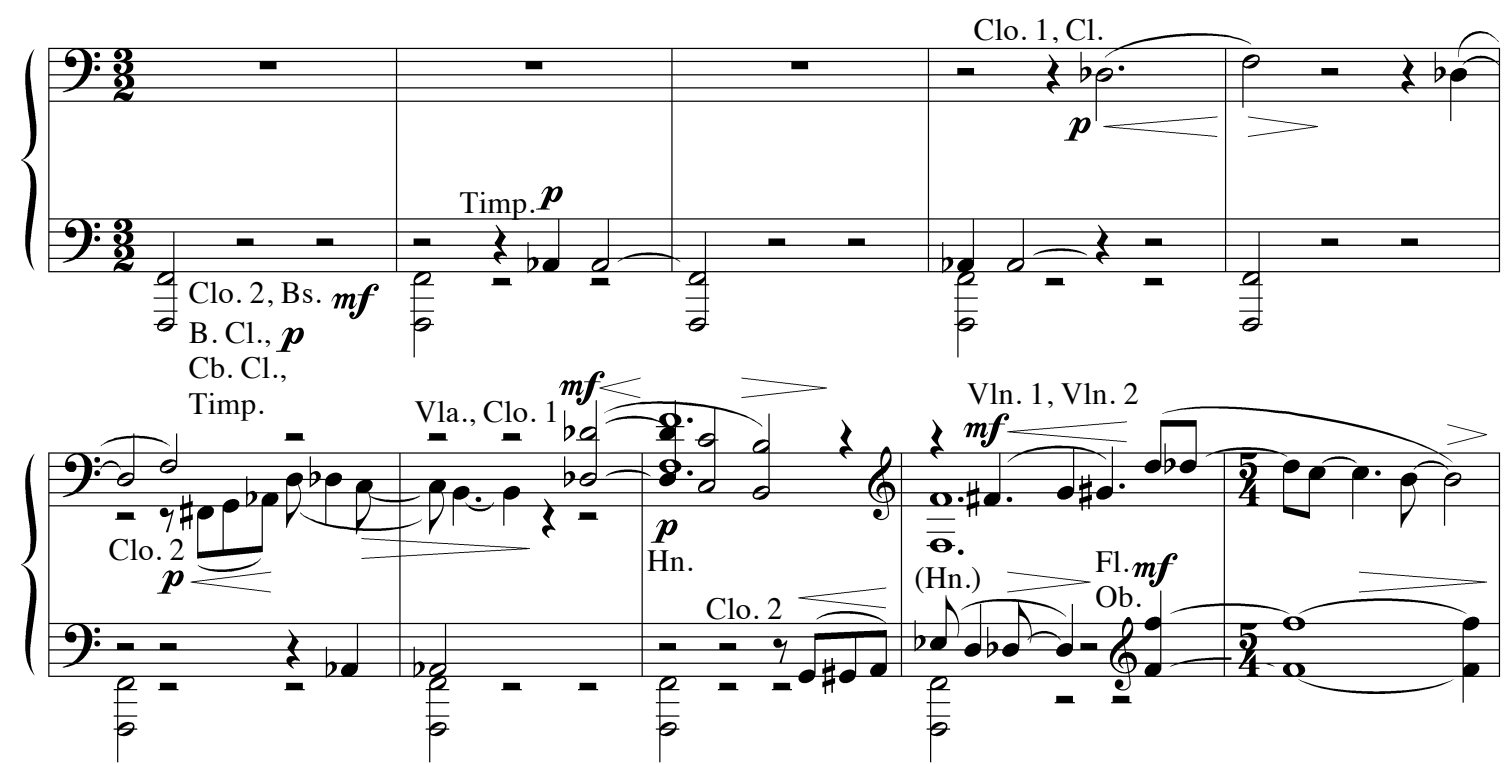

EXAmPle 1. Penderecki, Violin CONCERTO (No. 1), MM. 1-10
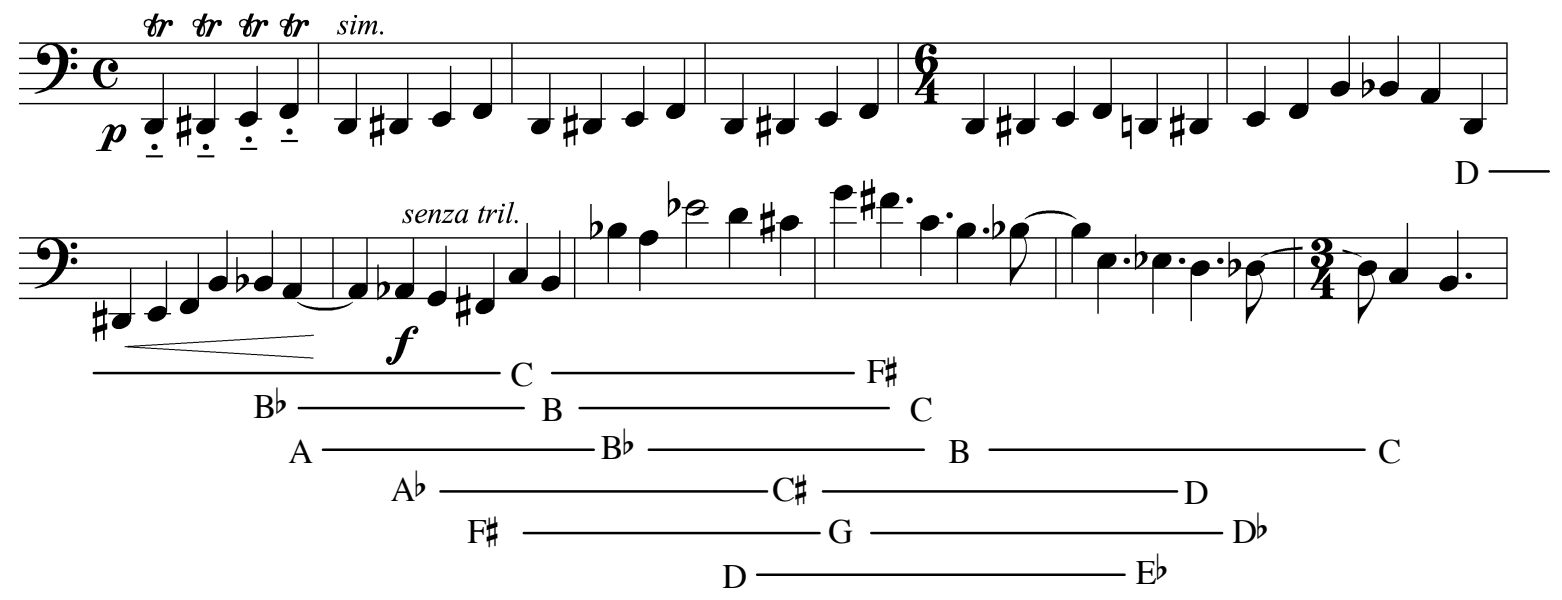

EXAMPLE 2. PENDERECKI, VIOLIN CONCERTO, MM. 11-22, CONTRABASS

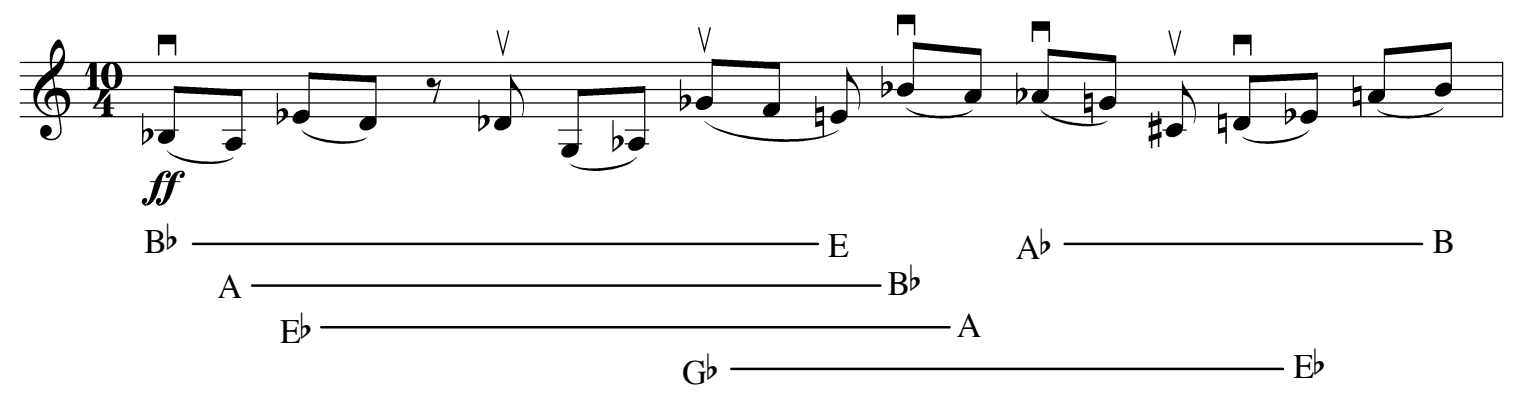

EXAMPLE 3. PENDERECKI, ViOLIN CONCERTO, M. 273 

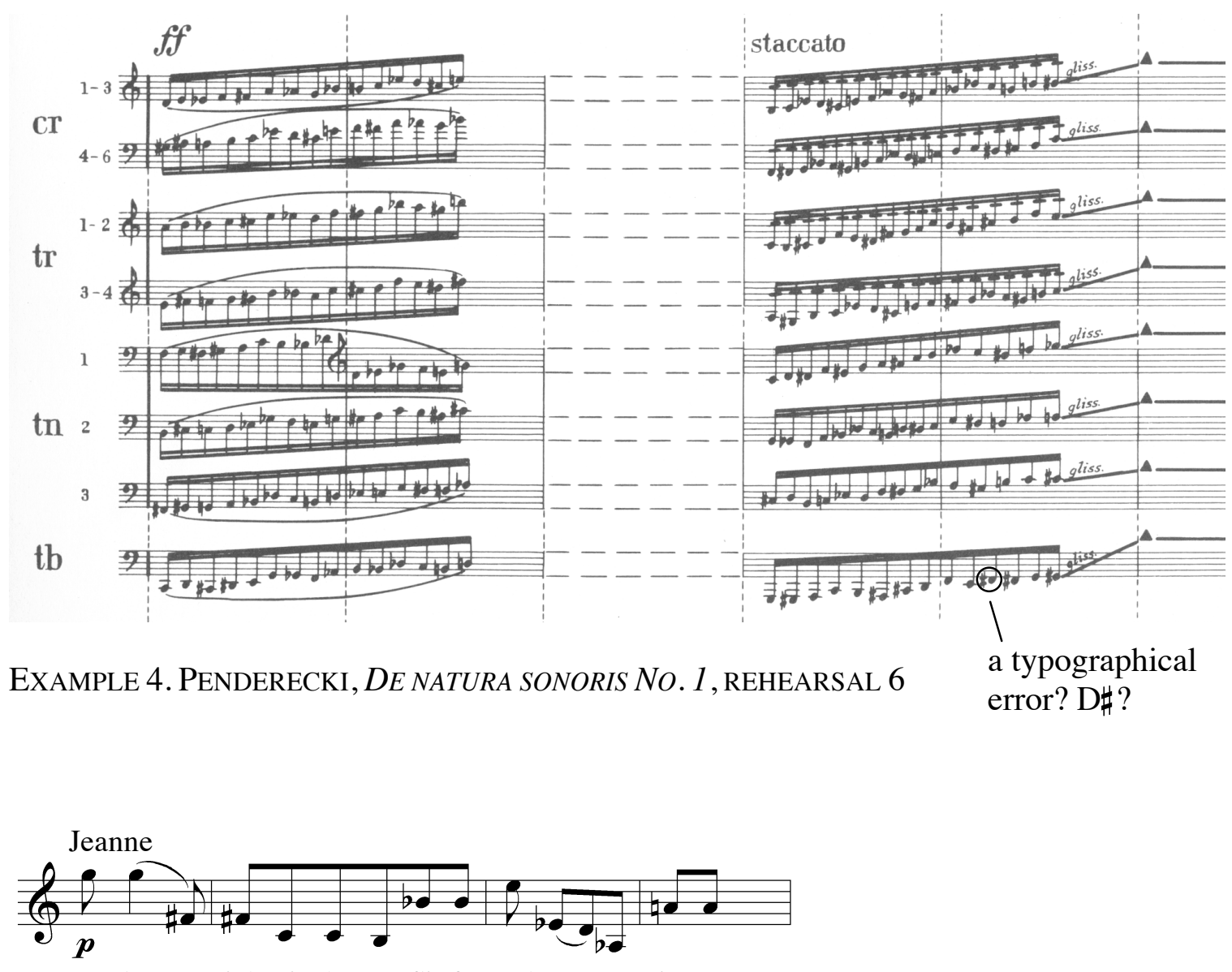

Das Blut wird zwi-schen uns flie-ßen und uns ver- ein-en.

EXAMPLE 5. PENDERECKI, THE DEVILS OF LOUDON, 5 MEASURES BEFORE REHEARSAL 4

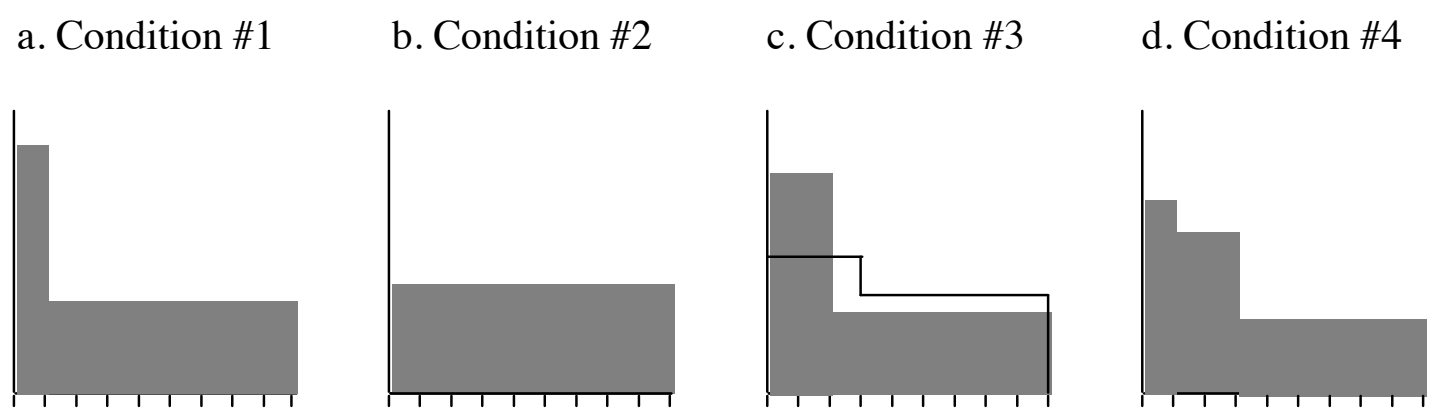

EXAMPLE 6. GRAPHIC DEPICTIONS OF THE FOUR CONDITIONS FOR AN ANALOGY TO TONAL EXPECTATIONS 
Murphy, Scott. "A Model of Melodic Expectation in Some Neo-Romantic Music of Penderecki," Perspectives of New Music 25/1 (Winter 2007): 6-42.

a. Measures 6-7, 'cello 2

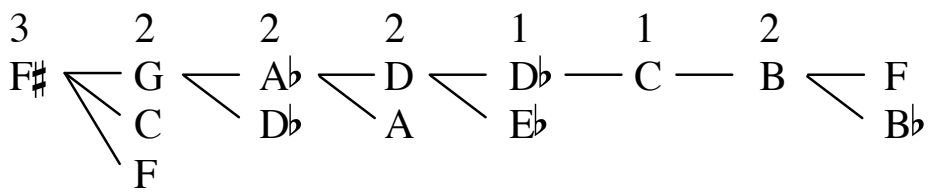

"I" "V" "I"

b. Measures $8-9$, 'cello 2

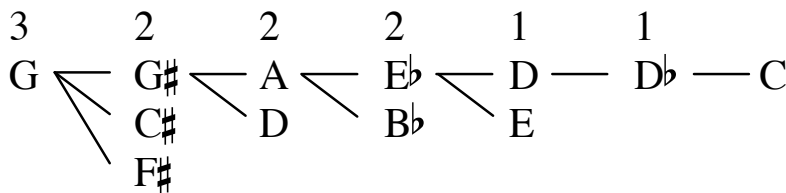

"I"

"V"

EXAMPLE 7. EXPECTANCY ANALYSES OF THE OPENING OF THE VIOLIN CONCERTO

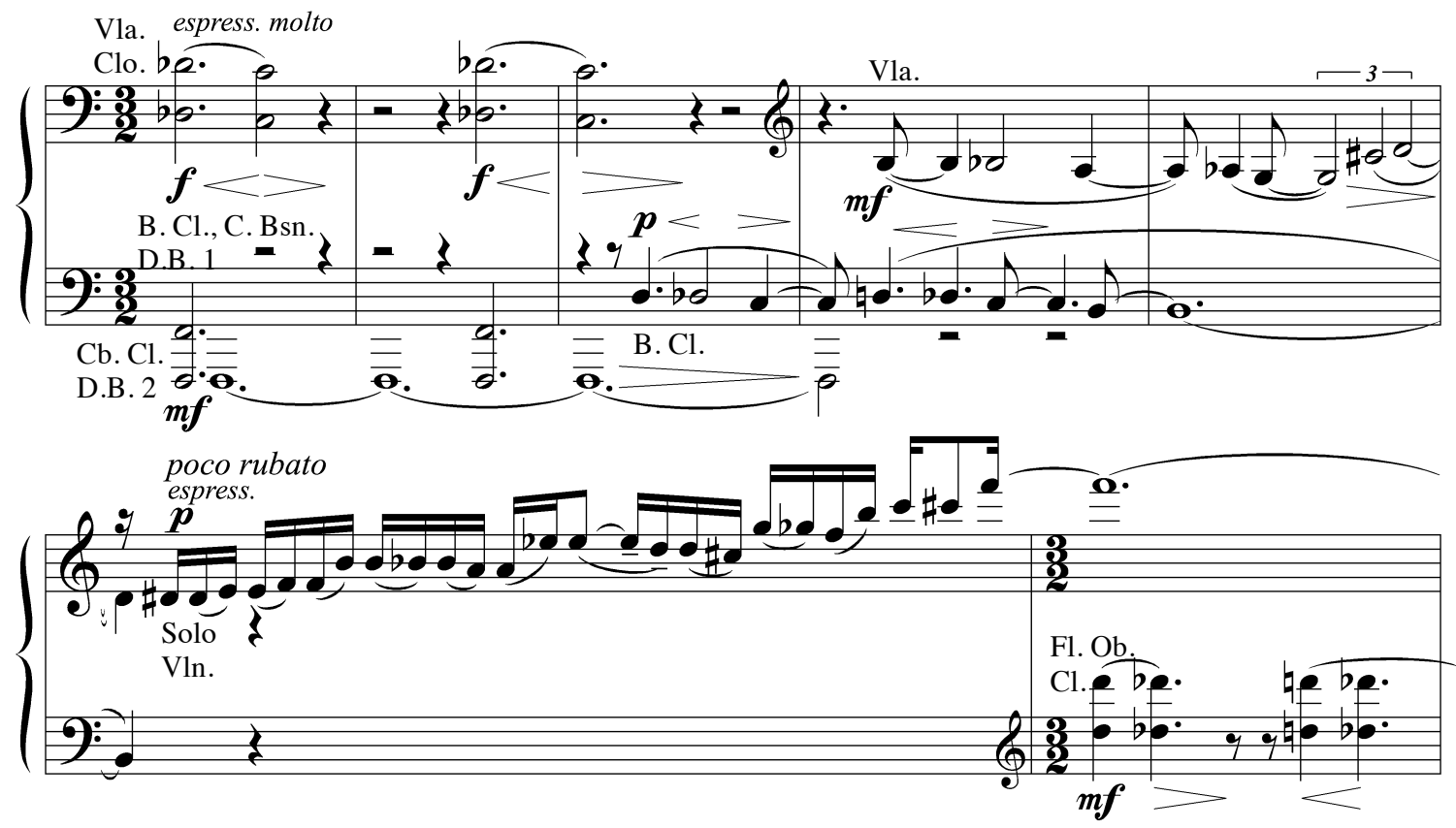

EXAMPLE 8. ViOLIN CONCERTO, MM. 23-29 


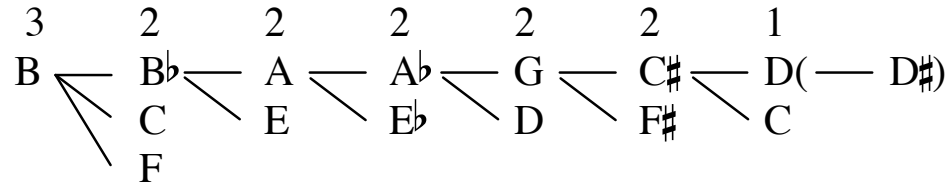

"I"

"V"

EXAMPLE 9. EXPECTANCY ANALYSIS OF VIOLIN CONCERTO, MM. 23-29

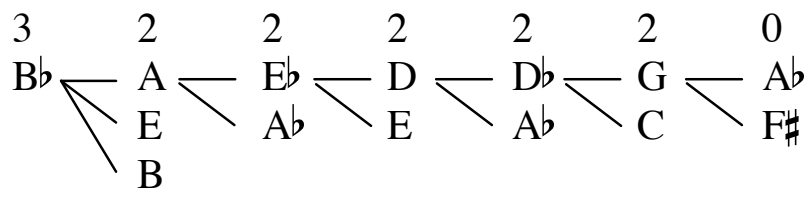

"I"

"I"

EXAMPLE 10. EXPECTANCY ANALYSIS OF VIOLIN CONCERTO, BEGINNINGS OF MM. 273 AND 563

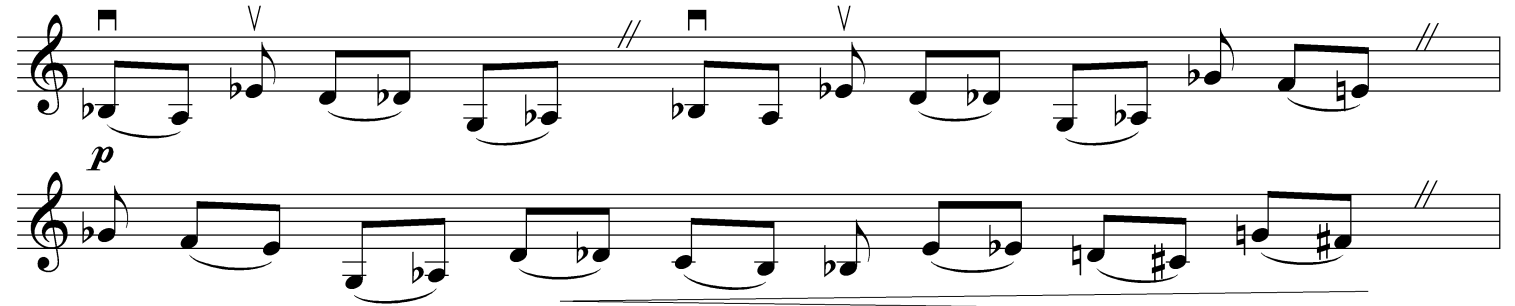

EXAMPLE 11. PENDERECKI, Violin CONCERTO, BEGINNING OF M. 563 (THIRD AND FINAL CADENZA)

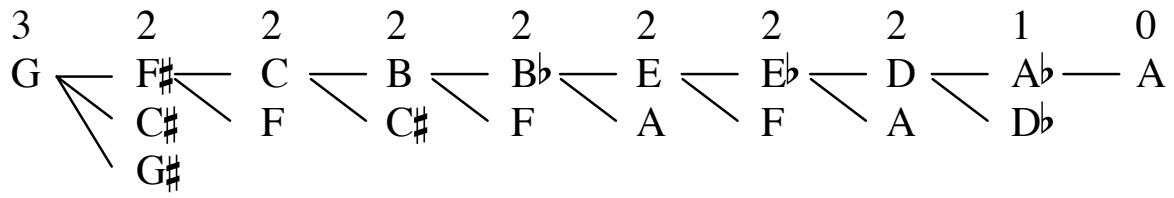

"I"

"V" "I"

EXAMPLE 12. EXPECTANCY ANALYSIS OF EXAMPLE 5 


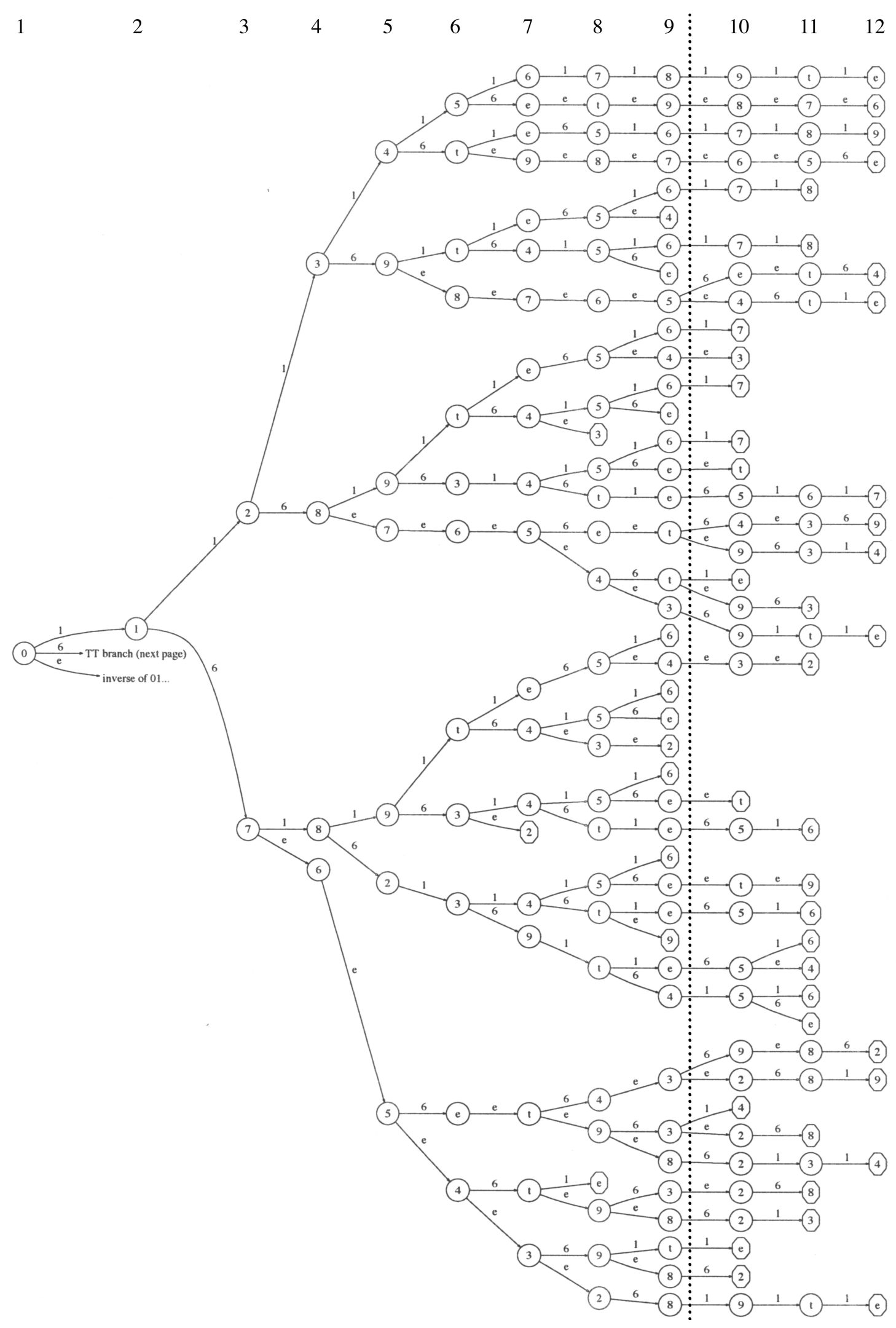

EXAMPLE 13. THE PENDERECKI TREE (THE SEMITONE BRANCH) 
Murphy, Scott. "A Model of Melodic Expectation in Some Neo-Romantic Music of Penderecki," Perspectives of New Music 25/1 (Winter 2007 ): 6-42. Publisher's Official Version: http://www.perspectivesofnewmusic.org/. Open Access version: http://kuscholarworks.ku.edu/dspace/.

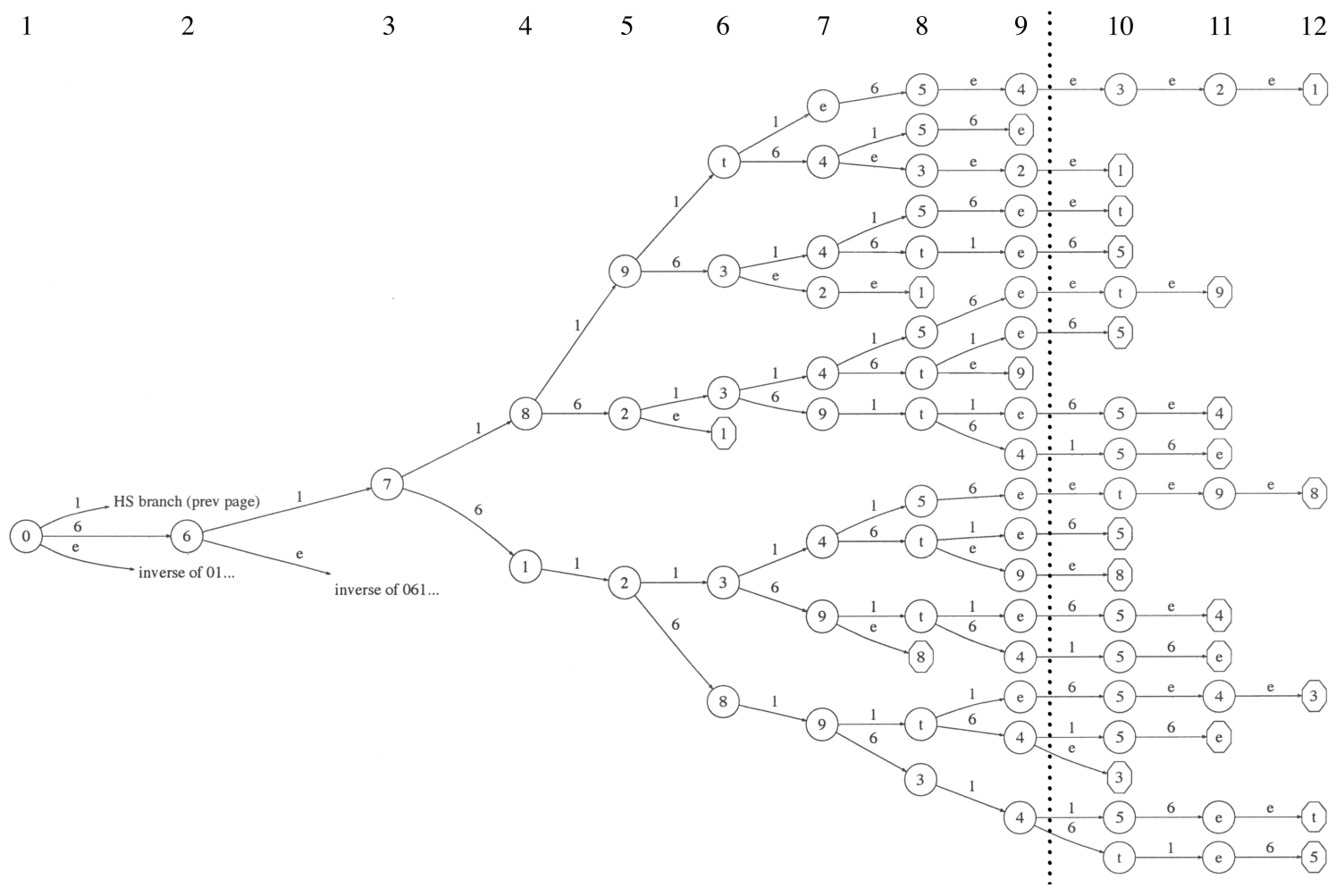

EXAMPLE 13 CONTINUED (THE TRITONE BRANCH) 
Murphy, Scott. "A Model of Melodic Expectation in Some Neo-Romantic Music of Penderecki," Perspectives of New Music 25/1 (Winter 2007): 6-42.

Publisher's Official Version: http://www.perspectivesofnewmusic.org/. Open Access version: http://kuscholarworks.ku.edu/dspace/.

\section{$2-1 \quad 3-1 \quad 4-2 \quad 5-4 \quad 6-7 \quad 7-11$}

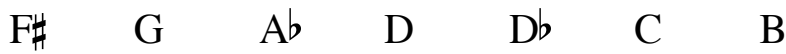

$\begin{array}{llllll}.02 & .07 & .53 & 1 & 1 & .33\end{array}$

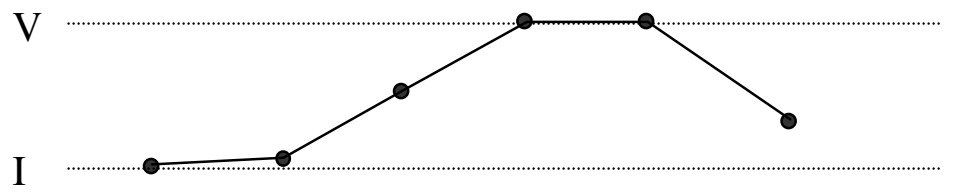

EXAMPlE 14. BiASED ANALYSIS OF ViOLIN CONCERTO, MM. 6-7, 'CELlO 2 (COMPARE WITH EXAMPLE 7A)

\section{$2-1 \quad 3-2 \quad 4-3 \quad 5-5 \quad 6-9 \quad 7-15$}

$\begin{array}{ccccccc}\mathrm{Bb} & \mathrm{A} & \mathrm{Eb} & \mathrm{D} & \mathrm{D} b & \mathrm{G} & \mathrm{Ab} \\ & .02 & .38 & .35 & .27 & .83 & 0\end{array}$

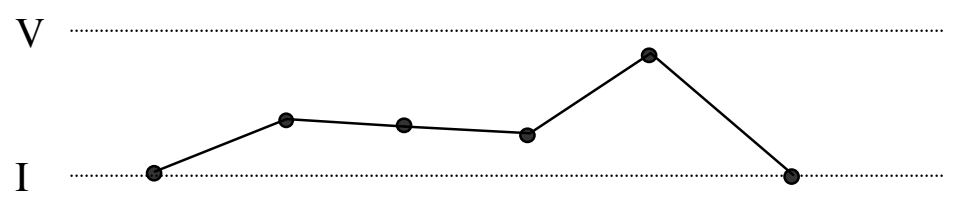

EXAMPLE 15. BIASED ANALYSIS OF VIOLIN CONCERTO, BEGINNINGS OF MM. 273 AND 563 (COMPARE WITH EXAMPLE 10) 
Murphy, Scott. "A Model of Melodic Expectation in Some Neo-Romantic Music of Penderecki," Perspectives of New Music 25/1 (Winter 2007 ): 6-42. Publisher's Official Version: http://www.perspectivesofnewmusic.org/. Open Access version: http://kuscholarworks.ku.edu/dspace/.

\section{APPENDIX}

\begin{tabular}{|c|c|c|c|c|c|c|}
\hline LB & $\overline{P F}$ & INT & $\begin{array}{l}\text { \# PC } \\
\text { CONT }\end{array}$ & \# MEL CONT & BIAS & \\
\hline $2-1$ & 01 & 1 & 2 & 111 & $55(3-1), 56(3-2)$ & .02 \\
\hline $2-2$ & 06 & 6 & 2 & 108 & $54(3-3), 54(3-3)$ & 0 \\
\hline $3-1$ & 012 & 11 & 2 & 54 & $28(4-1), 26(4-2)$ & .07 \\
\hline $3-2$ & 017 & 16 & 2 & 55 & $34(4-3), 21(4-4)$ & .38 \\
\hline $3-3$ & 067 & 61 & 2 & 53 & $32(4-5), 21(4-6)$ & .34 \\
\hline $4-1$ & 0123 & 111 & 2 & 27 & $15(5-1), 12(5-2)$ & .2 \\
\hline $4-2$ & 0128 & 116 & 2 & 25 & $17(5-3), 8(5-4)$ & .53 \\
\hline $4-3$ & 0178 & 161 & 2 & 33 & $20(5-5), 13(5-6)$ & .35 \\
\hline $4-4 z$ & 0176 & $16 \mathrm{e}$ & 1 & 20 & $20(5-7)$ & 1 \\
\hline $4-5$ & 0678 & 611 & 2 & 31 & $18(5-8), 13(5-9)$ & .28 \\
\hline $4-6 z$ & 0671 & 616 & 1 & 20 & $20(5-10)$ & 1 \\
\hline $5-1$ & 01234 & 1111 & 2 & 14 & $7(6-1), 7(6-2)$ & 0 \\
\hline $5-2$ & 01239 & 1116 & 2 & 11 & $7(6-3), 4(6-4)$ & .43 \\
\hline $5-3$ & 01289 & 1161 & 2 & 16 & $9(6-5), 7(6-6)$ & .22 \\
\hline $5-4$ & 01287 & $116 \mathrm{e}$ & 1 & 7 & $7(6-7)$ & 1 \\
\hline $5-5$ & 01789 & 1611 & 2 & 19 & $11(6-8), 8(6-9)$ & .27 \\
\hline $5-6$ & 01782 & 1616 & 1 & 12 & $12(6-10)$ & 1 \\
\hline $5-7 z$ & 01765 & $16 \mathrm{ee}$ & 2 & 19 & $7(6-11), 12(6-12)$ & .42 \\
\hline $5-8$ & 06789 & 6111 & 2 & 17 & $9(6-13), 8(6-14)$ & .11 \\
\hline $5-9$ & 06782 & 6116 & 2 & 12 & $11(6-15), 1(6-16)$ & .91 \\
\hline $5-10 z$ & 06712 & 6161 & 2 & 19 & $12(6-17), 7(6-18)$ & .42 \\
\hline $6-1$ & 012345 & 11111 & 2 & 6 & $3(7-1), 3(7-2)$ & 0 \\
\hline $6-2$ & $01234 t$ & 11116 & 2 & 6 & $3(7-3), 3(7-4)$ & 0 \\
\hline $6-3$ & $01239 t$ & 11161 & 2 & 6 & $3(7-5), 3(7-6)$ & 0 \\
\hline $6-4$ & 012398 & $1116 \mathrm{e}$ & 1 & 3 & $3(7-7)$ & 1 \\
\hline $6-5$ & $01289 t$ & 11611 & 2 & 8 & $3(7-8), 5(7-9)$ & .4 \\
\hline $6-6$ & 012893 & 11616 & 1 & 6 & $6(7-10)$ & 1 \\
\hline $6-7 z_{1}$ & 012876 & $116 \mathrm{ee}$ & 1 & 6 & $6(7-11)$ & 1 \\
\hline $6-8$ & $01789 t$ & 16111 & 2 & 10 & $4(7-12), 6(7-13)$ & .33 \\
\hline $6-9$ & 017893 & 16116 & 2 & 7 & $6(7-14), 1(7-15)$ & .83 \\
\hline $6-10$ & 017823 & 16161 & 2 & 11 & $7(7-16), 4(7-17)$ & .43 \\
\hline $6-11 z_{1}$ & $01765 \mathrm{e}$ & 16 ee6 & 1 & 6 & $6(7-18)$ & 1 \\
\hline $6-12 z_{2}$ & 017654 & 16 eee & 2 & 11 & $5(7-19), 6(7-20)$ & .17 \\
\hline $6-13$ & $06789 \mathrm{t}$ & 61111 & 2 & 8 & $3(7-21), 5(7-22)$ & .4 \\
\hline $6-14$ & 067893 & 61116 & 2 & 7 & $5(7-23), 2(7-24)$ & .6 \\
\hline $6-15$ & 067823 & 61161 & 2 & 10 & $6(7-25), 4(7-26)$ & .33 \\
\hline $6-16$ & 067821 & $6116 \mathrm{e}$ & 0 & 0 & & 0 \\
\hline $6-17 z_{2}$ & 067123 & 61611 & 2 & 11 & $6(7-27), 5(7-28)$ & .17 \\
\hline $6-18 z_{1}$ & 067128 & 61616 & 1 & 6 & $6(7-29)$ & 1 \\
\hline $7-1 z_{1}$ & 0123456 & 111111 & 1 & 2 & $2(8-1)$ & 1 \\
\hline $7-2 z_{1}$ & $012345 \mathrm{e}$ & 111116 & 1 & 2 & $2(8-2)$ & 1 \\
\hline $7-3 z_{2}$ & 01234te & 111161 & 1 & 2 & $2(8-3)$ & 1 \\
\hline $7-4$ & $01234 \mathrm{t} 9$ & $11116 \mathrm{e}$ & 1 & 2 & $2(8-4)$ & 1 \\
\hline $7-5 z_{3}$ & 01239te & 111611 & 1 & 2 & $2(8-5)$ & 1 \\
\hline $7-6$ & $01239 t 4$ & 111616 & 1 & 2 & $2(8-6)$ & 1 \\
\hline $7-7$ & 0123987 & $1116 \mathrm{ee}$ & 1 & 2 & $2(8-7)$ & 1 \\
\hline $7-8$ & 01289te & 116111 & 1 & 2 & $2(8-8)$ & 1 \\
\hline $7-9$ & $01289 t 4$ & 116116 & 2 & 4 & $3(8-9), 1(8-10)$ & .67 \\
\hline $7-10$ & 0128934 & 116161 & 2 & 5 & $3(8-11), 2(8-12)$ & .33 \\
\hline
\end{tabular}


Murphy, Scott. "A Model of Melodic Expectation in Some Neo-Romantic Music of Penderecki," Perspectives of New Music 25/1 (Winter 2007 ): $6-42$. Publisher's Official Version: http://www.perspectivesofnewmusic.org/. Open Access version: http://kuscholarworks.ku.edu/dspace/.

\begin{tabular}{|c|c|c|c|c|c|c|}
\hline LB & $\mathbf{P F}$ & INT & $\begin{array}{l}\text { \# PC } \\
\text { CONT }\end{array}$ & \# MEL CONT & BIAS & \\
\hline $7-11 z_{4}$ & 0128765 & 116eee & 2 & 5 & $2(8-13), 3(8-14)$ & .33 \\
\hline $7-12 z_{3}$ & 01789te & 161111 & 1 & 3 & $3(8-15)$ & 1 \\
\hline $7-13$ & $01789 \mathrm{t} 4$ & 161116 & 2 & 5 & $3(8-16), 2(8-17)$ & .33 \\
\hline $7-14$ & 0178934 & 161161 & 2 & 5 & $3(8-18), 2(8-19)$ & .33 \\
\hline $7-15$ & 0178932 & $16116 \mathrm{e}$ & 0 & 0 & & 0 \\
\hline $7-16$ & 0178234 & 161611 & 2 & 6 & $3(8-20), 3(8-21)$ & 0 \\
\hline $7-17$ & 0178239 & 161616 & 1 & 3 & $3(8-22)$ & 1 \\
\hline $7-18 z_{4}$ & 01765 et & $16 e e 6 \mathrm{e}$ & 2 & 5 & $2(8-23), 3(8-24)$ & .33 \\
\hline $7-19 z_{5}$ & $017654 \mathrm{t}$ & 16 eee6 & 2 & 4 & $1(8-25), 3(8-26)$ & .67 \\
\hline $7-20 z_{6}$ & 0176543 & 16eeee & 2 & 5 & $3(8-27), 2(8-28)$ & .33 \\
\hline $7-21 z_{2}$ & 06789te & 611111 & 1 & 2 & $2(8-29)$ & 1 \\
\hline $7-22$ & 06789t4 & 611116 & 2 & 4 & $2(8-30), 2(8-31)$ & 0 \\
\hline $7-23$ & 0678934 & 611161 & 2 & 4 & $2(8-32), 2(8-33)$ & 0 \\
\hline $7-24$ & 0678932 & $61116 \mathrm{e}$ & 1 & 1 & $1(8-34)$ & 1 \\
\hline $7-25$ & 0678234 & 611611 & 2 & 5 & $2(8-35), 3(8-36)$ & .33 \\
\hline $7-26$ & 0678239 & 611616 & 1 & 3 & $3(8-37)$ & 1 \\
\hline $7-27 z_{6}$ & 0671234 & 616111 & 2 & 5 & $2(8-38), 3(8-39)$ & .33 \\
\hline $7-28 z_{5}$ & 0671239 & 616116 & 2 & 4 & $3(8-40), 1(8-41)$ & .67 \\
\hline $7-29 z_{4}$ & 0671289 & 616161 & 2 & 5 & $3(8-42), 2(8-43)$ & .33 \\
\hline $8-1 z_{1}$ & 01234567 & 1111111 & 1 & 1 & $1(9-1)$ & 1 \\
\hline $8-2 z_{5}$ & $012345 \mathrm{et}$ & $111116 \mathrm{e}$ & 1 & 1 & $1(9-2)$ & 1 \\
\hline $8-3 z_{1}$ & 01234 te 5 & 1111616 & 1 & 1 & $1(9-3)$ & 1 \\
\hline $8-4$ & $01234 t 98$ & 11116 ee & 1 & 1 & $1(9-4)$ & 1 \\
\hline $8-5$ & 01239 te 5 & 1116116 & 2 & 2 & $1(9-5), 1(9-6)$ & 0 \\
\hline $8-6$ & $01239 t 45$ & 1116161 & 2 & 2 & $1(9-7), 1(9-8)$ & 0 \\
\hline $8-7 z_{2}$ & 01239876 & 1116eee & 1 & 1 & $1(9-9)$ & 1 \\
\hline $8-8$ & 01289te5 & 1161116 & 2 & 2 & $1(9-10), 1(9-11)$ & 0 \\
\hline $8-9$ & $01289 t 45$ & 1161161 & 2 & 2 & $1(9-12), 1(9-13)$ & 0 \\
\hline $8-10$ & $01289 t 43$ & $116116 \mathrm{e}$ & 0 & 0 & & 0 \\
\hline $8-11$ & 01289345 & 1161611 & 2 & 2 & $1(9-14), 1(9-15)$ & 0 \\
\hline $8-12$ & $0128934 \mathrm{t}$ & 1161616 & 1 & 1 & $1(9-16)$ & 1 \\
\hline $8-13 z_{2}$ & $0128765 \mathrm{e}$ & 116eee6 & 1 & 1 & $1(9-17)$ & 1 \\
\hline $8-14 z_{3}$ & 01287654 & 116eeee & 2 & 2 & $1(9-18), 1(9-19)$ & 0 \\
\hline $8-15$ & 01789 te 5 & 1611116 & 2 & 2 & $1(9-20), 1(9-21)$ & 0 \\
\hline $8-16$ & $01789 t 45$ & 1611161 & 2 & 2 & $1(9-22), 1(9-23)$ & 0 \\
\hline $8-17$ & $01789 t 43$ & $161116 \mathrm{e}$ & 1 & 1 & $1(9-24)$ & 1 \\
\hline $8-18$ & 01789345 & 1611611 & 2 & 2 & $1(9-25), 1(9-26)$ & 0 \\
\hline 8-19 & $0178934 \mathrm{t}$ & 1611616 & 1 & 1 & $1(9-27)$ & 1 \\
\hline $8-20$ & 01782345 & 1616111 & 2 & 2 & $1(9-28), 1(9-29)$ & 0 \\
\hline $8-21$ & $0178234 \mathrm{t}$ & 1616116 & 2 & 2 & $1(9-30), 1(9-31)$ & 0 \\
\hline $8-22$ & $0178239 \mathrm{t}$ & 1616161 & 2 & 2 & $1(9-32), 1(9-33)$ & 0 \\
\hline $8-23 z_{2}$ & 01765 et 4 & 16 ee6e6 & 1 & 1 & $1(9-34)$ & 1 \\
\hline $8-24 z_{3}$ & 01765 et9 & 16ee6ee & 2 & 2 & $1(9-35), 1(9-36)$ & 0 \\
\hline $8-25 z_{4}$ & 017654te & 16eee61 & 0 & 0 & & 0 \\
\hline $8-26$ & $017654 \mathrm{t} 9$ & 16 eee6e & 2 & 2 & $1(9-37), 1(9-38)$ & 0 \\
\hline $8-27$ & 01765439 & 16 eeee6 & 2 & 2 & $1(9-39), 1(9-40)$ & 0 \\
\hline $8-28$ & 01765432 & 16eeeee & 1 & 1 & $1(9-41)$ & 1 \\
\hline $8-29 z_{5}$ & 06789 te 5 & 6111116 & 1 & 1 & $1(9-42)$ & 1 \\
\hline $8-30$ & $06789 t 45$ & 6111161 & 1 & 1 & $1(9-43)$ & 1 \\
\hline $8-31$ & $06789 \mathrm{t} 43$ & $611116 \mathrm{e}$ & 1 & 1 & $1(9-44)$ & 1 \\
\hline $8-32$ & 06789345 & 6111611 & 1 & 1 & $1(9-45)$ & 1 \\
\hline
\end{tabular}


Murphy, Scott. "A Model of Melodic Expectation in Some Neo-Romantic Music of Penderecki," Perspectives of New Music 25/1 (Winter 2007): 6-42.

Publisher's Official Version: http://www.perspectivesofnewmusic.org/. Open Access version: http://kuscholarworks.ku.edu/dspace/.

\begin{tabular}{|l|l|l|l|l|l|l|}
\hline LB & PF & INT & $\begin{array}{l}\text { \# PC } \\
\text { CONT }\end{array}$ & \# MEL CONT & \multicolumn{2}{l|}{ BIAS } \\
\hline $8-33$ & $0678934 \mathrm{t}$ & 6111616 & 1 & 1 & $1(9-46)$ & 1 \\
\hline $8-34 \mathrm{z}_{4}$ & 06789321 & $61116 \mathrm{ee}$ & 0 & 0 & & 0 \\
\hline $8-35$ & 06782345 & 6116111 & 1 & 1 & $1(9-47)$ & 1 \\
\hline $8-36$ & $0678234 \mathrm{t}$ & 6116116 & 2 & 2 & $1(9-48), 1(9-49)$ & 0 \\
\hline $8-37$ & $0678239 \mathrm{t}$ & 6116161 & 2 & 2 & $1(9-50), 1(9-51)$ & 0 \\
\hline $8-38$ & 06712345 & 6161111 & 1 & 1 & $1(9-52)$ & 1 \\
\hline $8-39$ & $0671234 \mathrm{t}$ & 6161116 & 2 & 2 & $1(9-53), 1(9-54)$ & 0 \\
\hline $8-40$ & $0671239 \mathrm{t}$ & 6161161 & 2 & 2 & $1(9-55), 1(9-56)$ & 0 \\
\hline $8-41$ & 06712398 & $616116 \mathrm{e}$ & 0 & 0 & & 0 \\
\hline $8-42$ & $0671289 \mathrm{t}$ & 6161611 & 2 & 2 & $1(9-57), 1(9-58)$ & 0 \\
\hline $8-43$ & 06712893 & 6161616 & 1 & 1 & $1(9-59)$ & 1 \\
\hline
\end{tabular}


Murphy, Scott. "A Model of Melodic Expectation in Some Neo-Romantic Music of Penderecki," Perspectives of New Music 25/1 (Winter 2007$): 6-42$.

\section{NOTES}

This investigation was supported by the University of Kansas General Research Fund allocation \#2301406 and was first presented as "Penderecki's Melodic Tree: A Preliminary Report" at the "American Perspectives on Penderecki" Conference in Houston, Texas in October 2004. I thank Brian Bondari and Lon Mitchell for their support of this research, and Ray Robinson and Deron McGee for reading an earlier draft of this article.

1. The first four essays in the inaugural volume of Studies in Penderecki endeavor to categorize Penderecki's output in terms of stylistic periods. Tomaszewski (1998) calls the neo-Romantic period "Time of Dialog with the Rediscovered Past" (19761985), which begins with the Violin Concerto. Robinson (1998) also begins his period "Synchronization of a More Expressive Musical Language With the Elements of the Modern Style" (1975-1986) with the Violin Concerto, although he acknowledges that The Awakening of Jacob "paves the way for this new direction" (40). Chl'opicka (1998) calls the period "The Sphere of Neo-Romanticism" (19741980), and concentrates on how Paradise Lost and Symphony No. 2 (1980) exemplify this phase, but she includes the Violin Concerto in this phase as well. Schwinger (1998) simply dubs this period "Retrospectives," which spans the time from the Violin Concerto and Paradise Lost to the Te Deum (1980) and Symphony No. 2. Some also consider the start of this neo-Romantic period as the primary stylistic shift in the composer's oeuvre. Thomas (2001) divides a discussion of the music into two parts: music up to 1974, and music after 1974. In an interview with Penderecki, Robinson (1983a) notes that the composer himself singled out The Awakening of Jacob as the beginning of a second period.

2. Schwinger (1980) describes this new period as an exploration of "the realm of melody" (11), and suggests in Schwinger (1989) that the Violin Concerto draws "much more from the spring of strong melodic inspiration." (60) Robinson (1983b) finds that this period "owes much to post-Wagnerian chromaticism with its expressive lines, its lyrical outpouring, and its dramatic highlights." Bylander (2004) states that this new period replaces many of Penderecki's earlier innovations with "clearly defined, lyric melodies and traditional orchestration." (10)

3. This transition is immediately apparent by skimming three successive orchestral works: The Awakening of Jacob (1974) incorporates quarter tones or glissandi into nearly all of its melodic motions, but only 30 out of the 70 pages of Schott's full score of the Violin Concerto (1977) call for these microtonal elements, and they are completely absent in the Second Symphony (1980).

4. The term "concentration" is preferred to "saturation" from Morris (1983/1984), because Morris's rows are saturated with a single set-type of a particular cardinality, whereas Penderecki's melodies concentrate on two or three interval classes (set-types of cardinality 2 ). 
5. This is not unlike an acknowledgment of certain liberties some serial composers take with their realizations of a row.

6. Robinson (1998), 46.

7. This method of analysis is very similar to, although not equivalent to, the method used to measure pc diversity in Tenney (1977). Tenney assigns a non-duplicative pc succession to every pc in a Ruggles melody; the length of this succession is measured as the number of non-duplicating pcs that lead up to and include the pc. Although this is a sound method for computing an average pc diversity, it slightly undervalues how long, on average, a given non-duplicative pc succession will continue to be non-duplicative, which is more in accordance with the present interest in melodic expectancy.

8. Cowell (1930), 42: "Ruggles writes at least seven or eight different notes in a melody before allowing himself to repeat the same note, even in the octave." Seeger (1932), 582: "Then again, there are only twelve semitones to the octave and everyone knows that is a pitiful number, especially when you have eight octaves, and, at least theoretically, no melody [of Ruggles] may repeat a given tone unless nine or ten others have intervened." Tenney (1977) notes a gradual increase in the average length of non-duplicative pc successions: from 5.7 in the works from 19191923 to 8.89 in Organum (1944). However, Slottow (2003) recognizes that "Ruggles was quite flexible in his application of pitch-class nonrepetition. Regardless of the average number of intervening notes, the actual number fluctuates widely, and sometimes the method is suspended altogether in the interests of concentrated motivic repetition," (6) which, to use a concept introduced in this study, may be teased apart from the application of pitch-class nonrepetition as an interior repetition.

9. “Finally, a principle underlying many of Ives's structural models, self-generating patterns, and transformational relationships is that a variety of pitch classes should be involved. In many cases, this concern translates to some method of completing the aggregate, inviting provocative but usually unproductive comparisons with twelve-tone music. The comparisons are more apt with pre-twelve-tone music, where pitch-class saturation and equalization are common methods of denying tonal incursions.” Lambert (1997), 15.

10. "Emanations, with its two string orchestras tuned a semitone apart, thus paved the way for Anaklasis, Fonogrammi, and Tren ['Threnody'], works which use novel graphic notation and what was to become a characteristically broad-brush approach to musical materials and their development." Thomas (2001), 306.

11. Indeed, with the exception of the preference to realize these intervals as "small" registral intervals, one is strongly reminded of many of Webern's rows that have the same interval-class concentration. The second run in the first three horns (cr.) of 
Example 4 matches the row - and its overlapping $\mathrm{T}_{5}$ extension - from Webern's Variations op. 30.

12. Thomas (2001), 307.

13. Schwinger (1989), 230.

14. Robinson (1998), 46.

15. Lerdahl (2001) offers one set of quantitative measures for tonal expectations; see pp. 173-176 in particular.

16. Kostka and Payne (2004), 109.

17. Gauldin (2004), 121.

18. Piston (1941), 17. He ascribes this three-fold individual gradation to tonic as well!

19. Isaac Stern, the dedicatee of the concerto, plays the beginning of this third cadenza at $\bullet=106$, and pauses about one second for this first caesura on the work's first recording on 10 January 1978 (Minnesota Orchestra; Stanislaw Skrowaczewski, conductor).

20. This tree graph was drawn using Graphviz, an open source graph visualization application available at www.graphviz.org. I thank Lon Mitchell for bringing Graphviz to my attention.

21. Within each cardinality class, the equivalence classes are ordered by a base-3 interpretation of the interval series of its prime form, where $1 \rightarrow 0,6 \rightarrow 1$, and $e \rightarrow 2$.

22. Morris (1987), 107.

23. Two melodies $\mathrm{X}$ and $\mathrm{Y}$ in different melody classes will have the same tree structure for their continuation if the unordered content of $\mathrm{X}$ can be transposed or inverted into the unordered content of $\mathrm{Y}$, and the same transformation maps the last $\mathrm{pc}$ of $\mathrm{X}$ to the last pc of Y. For example, if one traces the incipits 0176 and 0671 on the Penderecki tree, one will see that the two branches that continue from these points have the same structure, even though the pc content is different. Here, $\mathrm{I}_{7}\{0167\}=$ $\{0167\}$ and $\mathrm{I}_{7}(6)=1$. Two such melodies, and the two melody classes to which they each belong, may be called "Z-related," if one is interested in transferring the spirit (but not the letter) of Forte's original relation to the Penderecki tree. These Zrelations are shown in the Appendix: any two melody-classes with the same $z_{n}$ are in a Z-relation.

24. For example, in The Awakening of Jacob, the section between rehearsal numbers 5a and 6 features the first and almost exclusive use of ic $1 / 6$ concentration in the work, in spite of the glissandi that fill in many of the intervals. Rehearsal 6 undoubtedly 
begins a new section, as the strings suddenly drop out and the sustaining winds begin to fan out into a cluster. The flute line, which begins six measures before rehearsal 6 as the highest and the slowest moving in the dense nine-voice texture and ends as the highest, is a terminal melody that ends with 6-16. The double bass line, which is the lowest sounding line throughout this section, is also a terminal melody that ends with 6-16. However, the contrapuntal density of this section makes it much more difficult to attend to these individual lines.

25. Incidentally, a maze or labyrinth without closed loops is isomorphic to a tree graph.

26. Penderecki (1998), 21.

27. Ibid, 24 .

28. Ibid, 39 .

29. According to Schoenberg (1984), "the construction of a basic set of twelve tones derives from the intention to postpone the repetition of every tone as long as possible. I have stated in my Harmonielehre that emphasis given to a tone by a premature repetition is capable of heightening it to the rank of tonic. But the regular application of a set of twelve tones emphasizes all the other tones in the same manner, thus depriving one single tone of the privilege of supremacy. It seemed in the first stages immensely important to avoid a similarity with tonality." (246)

30. Tomaszewski (1998), 23. 


\section{REFERENCES}

Bylander, Cindy. 2004. Krzysztof Penderecki: A Bio-Bibliography. Westport, Connecticut: Praeger Publishers.

Chl'opicka, Regina. 1998. "Stylistic Phases in the Work of Krzysztof Penderecki." In Studies in Penderecki 1, 51-63. Edited by Ray Robinson. Princeton, New Jersey: Prestige.

Cowell, Henry. 1930. New Musical Resources. New York: Knopf.

Gauldin, Robert. 2004. Harmonic Practice in Tonal Music. New York and London: W. W. Norton.

Kostka, Stefan and Dorothy Payne. 2004. Tonal Harmony: With an Introduction to Twentieth-Century Music. New York: McGraw-Hill.

Lambert, Philip. 1997. The Music of Charles Ives. New Haven: Yale University Press.

Lerdahl, Fred. 2001. Tonal Pitch Space. Oxford: Oxford University Press.

Morris, Robert. 1983/1984. "Set-Type Saturation Among Twelve-Tone Rows." Perspectives of New Music 22, nos. 1 and 2: 187-217. . 1987. Composition with Pitch Classes. New Haven: Yale University Press.

Penderecki, Krzysztof. 1998. Labyrinth of Time: Five Addresses for the End of the Millennium. Chapel Hill, North Carolina: Hinshaw Music.

Piston, Walter. 1941. Harmony. New York: W.W. Norton.

Robinson, Ray. 1983a. "Krzysztof Penderecki: An Interview and Analysis of Stabat Mater," The Choral Journal 24, no. 3 (November): ?. . 1983b. Krzysztof Penderecki: A Guide to His Works. Princeton, New Jersey: Prestige.

. 1998. "Penderecki's Musical Pilgrimage.” In Studies in Penderecki 1, 33-49. Edited by Ray Robinson. Princeton, New Jersey: Prestige Publications.

Schoenberg, Arnold. 1984. Style and Idea: Selected Writings of Arnold Schoenberg. Edited by Leonard Stein. Translated by Leo Black. Berkeley and Los Angeles: University of California Press.

Schwinger, Wolfram. 1980. Krzysztof Penderecki: List of Works. Mainz: Schott. . 1989. Krzysztof Penderecki: His Life and Work. Trans. William Mann. London: Schott. 

New Jersey: Prestige.

Seeger, Charles. 1932. "Carl Ruggles.” The Musical Quarterly 18, no. 4: ?.

Slottow, Stephen. 2003. "Wayward Compositional Practice in the Music of Carl Ruggles." Institute for Studies In American Music Newsletter 33, no. 1 (Fall): ?.

Tenney, James. 1977. "The Chronological Development of Carl Ruggles' Melodic Style." Perspectives of New Music 16, no. 1 (Fall-Winter): 36-69.

Thomas, Adrian. 2001. 'Penderecki, Krzyzstof,' The New Grove Dictionary of Music and Musicians. Edited by S. Sadie and J. Tyrrell. London: Macmillan.

Tomaszewski, Mieczlsl'aw. 1998. "Penderecki's Dialogues and Games with Time and Place on Earth.” In Studies in Penderecki 1, 13-32. Edited by Ray Robinson. Princeton, New Jersey: Prestige. 